\title{
Rapid water parcel transport across the Kuroshio Extension in the lower thermocline from dissolved oxygen measurements by Seaglider
}

\author{
Shigeki Hosoda ${ }^{1 *}$ (D, Ryuichiro Inoue ${ }^{1}$, Masami Nonaka ${ }^{2}$, Hideharu Sasaki ${ }^{2}$, Yoshikazu Sasai ${ }^{1}$ and Mizue Hirano ${ }^{1}$
}

\begin{abstract}
Small water parcels, which are characterized by a low salinity and high dissolved oxygen (DO) are observed by Seaglider in the main thermocline (26.0-27.0 $\left.\sigma_{\theta}\right)$ south of the Kuroshio Extension (KE), have horizontal and vertical scales of a few tens of kilometers and a few tens of meters, respectively. Water mass analyses revealed larger negative salinity anomalies $(<-0.05)$ and positive DO anomalies $\left(>15 \mu \mathrm{mol} \mathrm{kg}{ }^{-1}\right)$ than those of the surrounding water. The characteristics are similar to those of water mass with low salinity and high DO in the subpolar Northwestern Pacific Ocean. Additionally, higher DO anomaly water parcels appear in the upper layer $\left(<26.7 \sigma_{\theta}\right)$ while low salinity parcels appear in the lower layer $\left(>26.7 \sigma_{\theta}\right)$. Oxygen consumption rates from the apparent oxygen utility suggest that the small water parcels consume less oxygen than the surrounding water, implying that they migrate in a shorter time across the KE after subduction and their characteristics may reflect the sea surface temperature, salinity, and DO in the subduction region. Similar small water parcels represented by high-resolution numerical simulations indicate that they pass through the KE in 1 month. The simulations support the oxygen consumption rate from the Seaglider observations. The existence of a fast process for water mass migration via meso- and submesoscale subduction processes across the KE affects the amount, subduction, and exchange process of water mass. Our study indicates that a small water mass contributes to the exchange process across the KE rapidly, which had not been identified in previous studies. Consequently, detailed observations using multiple Seagliders should capture detailed spatial and temporal variability of the water mass exchange process.
\end{abstract}

Keywords: Seaglider, Small water parcels, Water mass exchange, Kuroshio Extension, Mesoscale eddy, Submesoscale, Dissolved oxygen

\section{Introduction}

Heat, freshwater, and material transports in the subsurface ocean play crucial roles in global climate change. As climate change evolves, they are being redistributed (e.g., Stocker 2013). In the western part of the ocean where a strong western boundary current exists, the water mass and materials are exchanged across the strong currents

\footnotetext{
* Correspondence: hosodas@jamstec.go.jp

'Research Institute for Global Change, Japan Agency for Marine-Earth Science and Technology, 2-15 Natsushima-cho, Yokosuka, Kanagawa 237-0061, Japan

Full list of author information is available at the end of the article
}

through a subduction process in the main thermocline (Marshall 1997; Williams 2001; Suga et al. 2008). This exchange significantly influences the climate system. In the North Pacific Ocean, the Kuroshio consists of the northwestern flank of the subtropical gyre with a warm and saline water stream to the east, while the Oyashio flows in the subpolar region of the North Pacific and consists of cold and fresher water flows with a higher dissolved oxygen (DO; Garcia et al. 2018) to the south along the east coast of Japan. These two major currents come in contact through the mixed water region 
(MWR), forming a strong meridional gradient of temperature and/or salinity front as the Kuroshio Extension (KE) (Talley et al. 1995; Yasuda et al. 1996).

The exchange process across the KE strongly affects both water mass modification and the dissipation of climate signals. A physical mechanism for water mass transformation across the KE had been suggested based on theories and observations (Marshall 1997; Williams 2001; Spall 1995; Yoshikawa et al. 2001, 2012; Kouketsu et al. 2007; Inoue et al. 2016b). High spatial density observations from the shipboard conductivitytemperature-depth-oxygen profiler (shipboard CTDO), and expendable conductivity-temperature-depth profiler (XCTD) (Yasuda et al. 1996; Okuda et al. 2001; Oka et al. 2009) found small water parcels with low potential vorticity (PV), high DO, and/or low salinity in the main thermocline around the MWR and KE. Recently, these results were supported by subsurface ocean mooring and biogeochemical (BGC) Argo float with DO sensors (Zhang et al. 2015; Nagano et al. 2016; Zhu et al. 2020).

Nagano et al. (2016) observed variability in the temperature, salinity, and DO for 10 months at the south of the KE using temporal and fine resolution observations of mooring data. Seasonal and interseasonal variations were detected during the passage of mesoscale eddies and submesoscale water parcels with high DO and low salinity. They intermittently observed a high DO signal at $600 \mathrm{~m}$. This was attributed to an elongated filament water mass of compressed subduction in the ageostrophic current across the KE flow with a detached cyclonic eddy from the meandering $\mathrm{KE}$, although low salinity small water parcels without high DO and low PV existed. Hence, meso- and submesoscale phenomena strongly affect water originating from the Oyashio, which is subducted and comes across the KE. Zhu et al. (2020) also observed the existence of similar mesoscale and submesoscale water parcels by long-term observational data of mooring arrays (2004-2006 and 2015-2019 around the KE), measuring temperature, salinity, and current meters, and described the dynamical characteristics of the subthermocline eddies in detail.

Focused observational approaches using lots of Argo floats equipped with DO sensor successfully captured meso- and submesoscale phenomena in the anticyclonic eddy at the south of KE first in 2011 (project name is "S1-INBOX"; Inoue et al. 2016a). Zhang et al. (2015) observed sub-thermocline eddies with low salinity and high DO water using frequent measurements of the DO Argo floats in an anticyclonic eddy south of the KE in spring 2014. The daily profile data showed that the observed small water parcels all had low PV. However, the layer of 26.5-26.8 $\sigma_{\theta}$ exhibited contrary characteristics. Some layers had low temperature, low salinity, and high DO, but others had high temperature, high salinity, and low DO. They concluded that the size of the detected water parcels was $150-190 \mathrm{~m}$ in the vertical direction and about $20 \mathrm{~km}$ in the horizontal direction. Thus, the water parcels resembled the submesoscale coherent vortices.

Li et al. (2017) investigated the distribution and frequency of submesoscale coherent vortices in the Northwestern North Pacific Ocean using accumulated Argo data. They identified 337 profiles that captured the submesoscale coherent vortices. Statistically, the size of water parcels was equivalent to the submesoscale from several to several tens of kilometers. The density surface was distributed over a wide range, and the $26.7 \sigma_{\theta}$ isopycnal surface was separated by their characteristics of the transition mode water (TRMW) for the upper layer and the North Pacific Intermediate Water (NPIW) for the lower layer. The seasonality of the occurrence rate was larger in the spring when the subducted water from the north of the KE was dominant. They concluded that water parcels play an important role in the cross-frontal flow across the KE. Given their geographic distributions and water mass characteristics, these submesoscale coherent vortices were termed the KE region intermediate-layer eddies as the Kiddies.

Some previous studies reported that water parcels are the key for heat and freshwater transport in large-scale phenomena. For example, Li et al. (2017) showed that water mass exchange in the subsurface with Kiddies contributes about $1 / 4$ of the large-scale processes in the Northwestern Pacific area based on accumulated historical Argo profiling data. On the contrary, vertically fine resolution profile data did not always capture small water parcels in the same area (e.g., Sukigara et al. 2011). Due to insufficient temporal and spatial resolutions and the difficulty detecting them, it is difficult to capture the actual shape and size. Additionally, the origin of small water parcels is unknown due to the variability in the characteristics. Furthermore, signals in the sea surface layer generated by small water parcels are generally weak, which makes detection from satellite observations difficult. Consequently, direct measurements of subsurface ocean observations are necessary (Johnson and McTaggart 2010; Bower et al. 2013).

Seaglider, which is an autonomous subsurface ocean observation tool, can measure the temperature, salinity, and DO from sea surface to 1000 dbar, diving more frequently than on-board CTD or other observation tools (Eriksen et al. 2001). Additionally, Seaglider successfully captured such small processes, which are described as the submesoscale coherent vortices (e.g., Pelland et al. 2013). Since target and observation missions can be controlled in real-time and operated over several months, Seaglider can perform long-term and quasi-stationary observations with a high spatial 
and temporal density compared to previous observation methods.

In this study, we focus on the detailed structures of small water parcels based on temporally and spatially frequent measurements by a Seaglider, including the DO data. Using multi-sensor measurements with DO and CTD, we suggest the relative age of small water parcels and qualitatively discuss the potential advection of a younger age water mass detected at the south of the KE in the subsurface layer.

The rest of this paper is organized as follows. First, we describe the data and method used. Second, the results of the Seaglider data analyses and the detailed characteristics of the water parcels are shown. Third, the possibility of detecting younger age water parcels in the main thermocline is considered by introducing the highresolution Ocean general circulation model For the Earth Simulator (OFES) analyses. Finally, we summarize this study and future perspectives of studying water parcels on the water mass exchange and modification.

\section{Method and experimental}

The Seaglider (manufactured by iRobot (now moved to Kongsberg), S/N: sg551) equipped with conductivity,

(a)

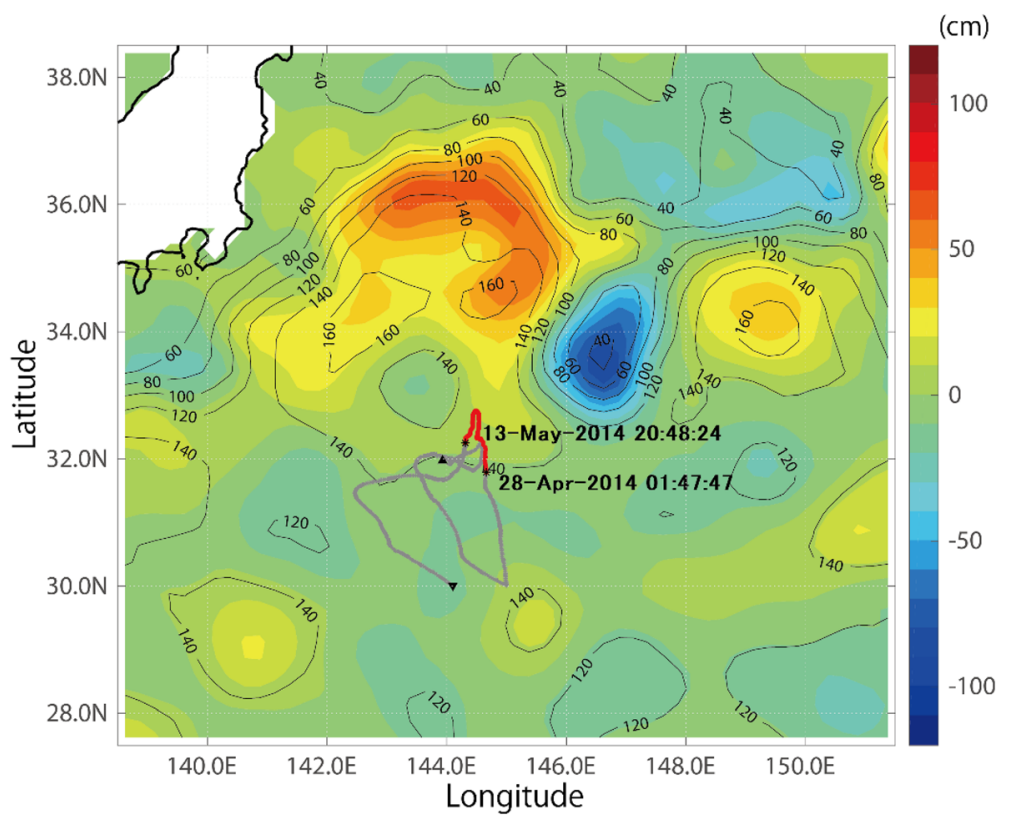

(b)

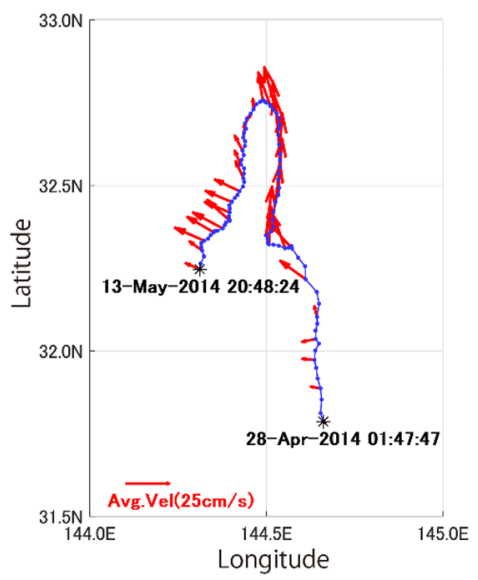

Fig. 1 a Trajectory of Seaglider for Feb. 27-Jun. 21 (gray line). Red line indicates focused period from Apr. 28-May 13. Background color and contours display mean sea level height anomaly (SSHA; cm) and absolute dynamic topography (ADT; $\mathrm{cm}$ ), respectively, on May 1 based on the $0.25^{\circ} \times 0.25^{\circ}$ daily mean merged gridded SSHA and ADT data set. b Vertically averaged horizontal current velocity $\left(\mathrm{cm} \mathrm{s}^{-1}\right.$; red arrow plotted every third profile) 

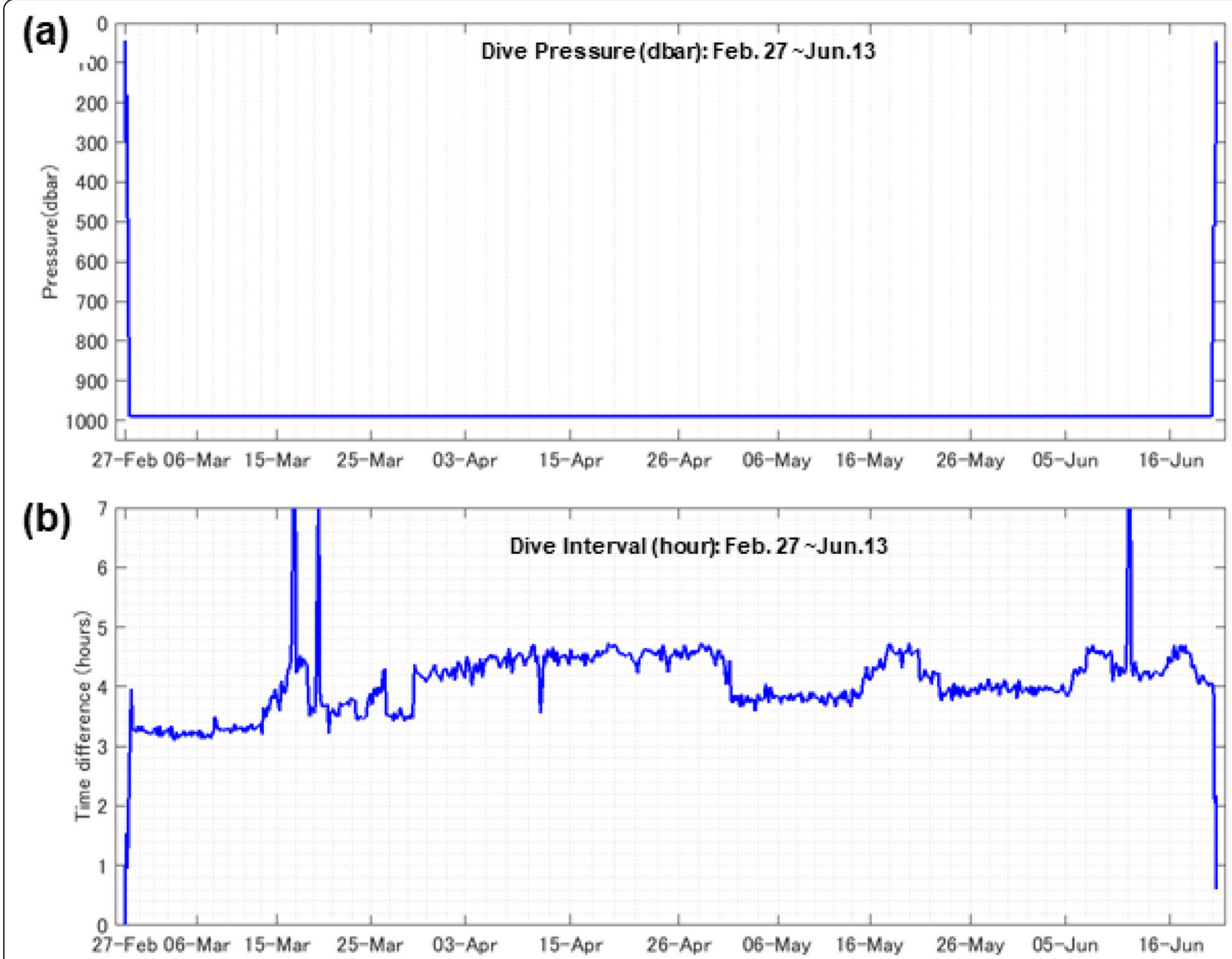

(c)

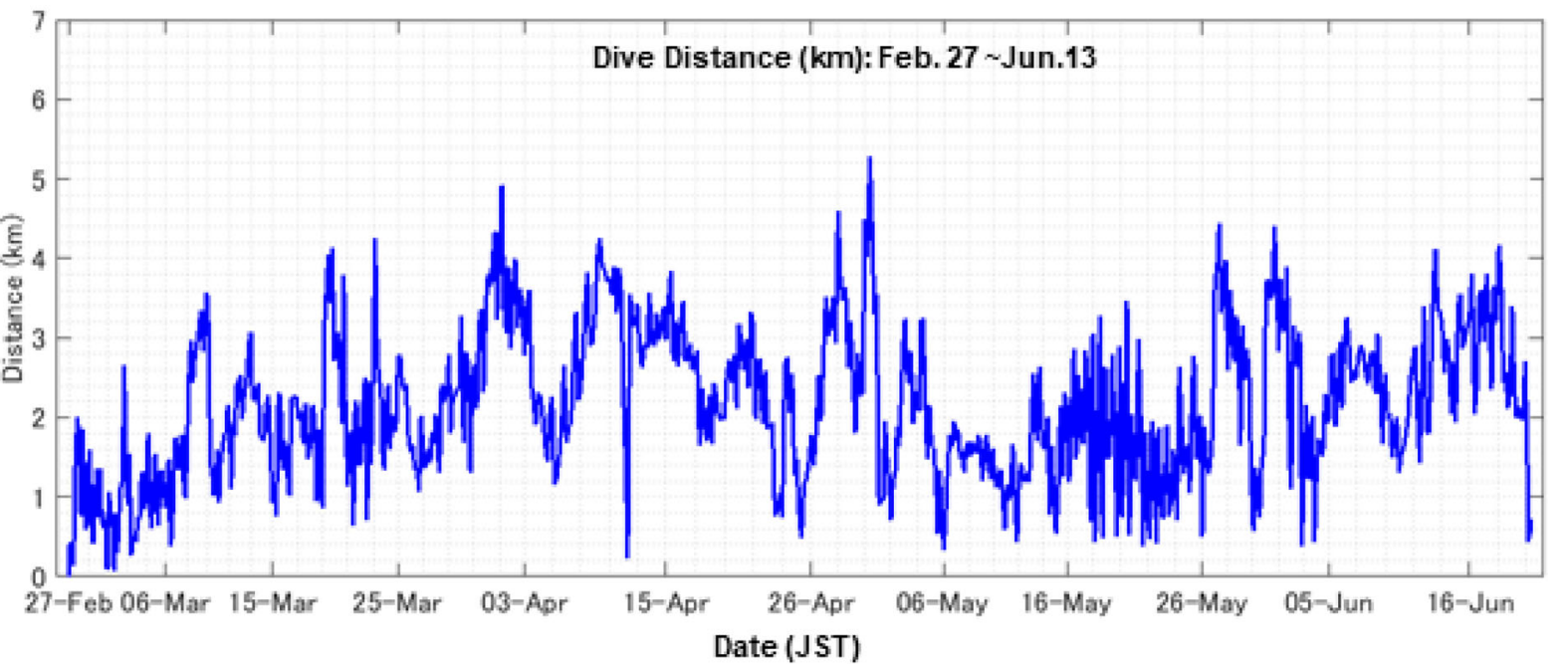

Fig. 2 a Dive pressure for each cast (dbar), b time interval for each cast (h), and c distance between each cast (km) through all Seaglider observations. Position, time, and pressure are measured at downward casts 
temperature, pressure, and DO sensors was operated at the south of the $\mathrm{KE}\left(30-32.5^{\circ} \mathrm{N}, 143-145^{\circ} \mathrm{E}\right)$ where mesoscale eddies are frequently detached. In the late winter-early summer (February 27 to June 21, 2014), 693 vertical casts from the sea surface down to 1000 dbar were obtained (Figs. 1a and 2a). Only the downcast profiles are used because the downcast speed is more stable than the upcast speed. The stability of each profile generally affects the accuracy as well as temporal and horizontal sampling intervals. Table 1 shows the vertical sampling intervals, which were finer resolution in the upper layer, while coarser one in the lower layer. Then, each profile is vertically interpolated every 1 dbar using the Akima spline (Akima 1970). Because the salinity and DO profiles at three stations were missed (dive no.: 131, 146, and 639), we fill these profiles with the linearly interpolated values using neighboring temporal profiles.

The accuracy of the Seaglider data is verified using the shipboard CTD profiles at the launched point (Hakuho Maru KH14-1 cruise; February 27, 2014) and at the recovery point (Kaiyo KY14-9 cruise; June 21, 2014). Specifically, the presence of a salinity bias is verified. All Seaglider profiles are judged to have a sufficient accuracy for the analyses. The average time interval between profiles was $4.0 \mathrm{~h}$, and the average spatial interval was 2.3 $\mathrm{km}$ (Fig. 2b, c). The intervals were mostly uniform.

For simplicity when analyzing the characteristics of the water parcels, all the profiles are converted to the horizontal distance originating from the launching point. Anomalies on isopycnals in the temperature, salinity, and DO are calculated based on the differences from their average values through the observation periods excluding the period when the small water parcels frequently appeared in Apr. 28-May 13 because the seasonal variation in the subsurface layer is below the detection limit for the small water parcels. The average values of the Seaglider itself are used to avoid superimposing the variability of the $\mathrm{KE}$ and long-term trend in the subsurface ocean. From the anomalies, the standard deviations are calculated for temperature, salinity, and DO. The results are used to evaluate extremely large positive or negative anomalies of each parameter.

We also use Argo float data to compare the characteristics and origin of small water parcels obtained from the Seaglider data. For comparison, data from each source are plotted as potential temperature-salinity

Table 1 Vertical sampling level of the Seaglider

\begin{tabular}{lll}
\hline Pressure (dbar) & Temp and Sal interval (dbar) & DO interval (dbar) \\
\hline $0-150$ & 5 & 10 \\
$150-300$ & 10 & 10 \\
$300-600$ & 20 & 20 \\
$600-1000$ & 30 & 30 \\
\hline
\end{tabular}

diagrams. We use the delayed-mode QCed Argo float data from the Global Data Assembly Center (GDAC; Argo 2000, 2020), which was observed during the formation of the deep winter mixed layer (January-April 2014 in the area of western North Pacific subtropical and subpolar regions: $25-45^{\circ} \mathrm{N}, 140-160^{\circ} \mathrm{E}$ ). To indicate the Seaglider position relative to the surface intensified mesoscale eddies, we use the absolute dynamic topography and the sea surface height anomaly (SSHA) from geoid using the OSTM/Jason-2 SSHA data, which is the multi-mission altimeter satellite $0.25^{\circ}$ daily-mean gridded sea surface heights. The values are computed with an optimal interpolation and a centered computation time window ( 6 days before and after the date). The data used here is from May 1, 2014 to trim the gridded data in $29.5-36.0^{\circ} \mathrm{N}, 139.0-149.0^{\circ} \mathrm{E}$ (Fig. 1a).

Furthermore, the daily mean averaging data from a hindcast numerical simulation (OFES: JAMSTEC 2009) is used, which realized meso- and submesoscale oceanic structures with a realistic topography. The model, which is based on the Modular Ocean Model (MOM3), covers the entire North Pacific between $100^{\circ} \mathrm{E}$ to $70^{\circ}$ $\mathrm{W}$ and $20^{\circ} \mathrm{S}$ to $68^{\circ} \mathrm{N}$. The horizontal resolution is $1 /$ $30^{\circ}$ and the 54 levels in the vertical cover the ocean from the surface to a realistic bottom topography (Masumoto et al. 2004; Sasaki et al. 2008). The $1 / 30^{\circ}$ OFES simulation can partially resolve the submesoscales, especially in the middle and low latitudes (Qiu et al. 2014; Sasaki et al. 2014). Atmospheric forcing of the simulation is from the 6-hourly Japanese 25-year reanalysis with a $1^{\circ}$ resolution (Onogi et al. 2007). A simple nitrogen-based nutrient-phytoplanktonzooplankton-detritus (NPZD) pelagic ecosystem model (Oschlies 2001) is included in the OFES simulation. The evolution of the biological tracer concentration is governed by advection-diffusion equations with source and sink terms (Sasai et al. 2006, 2010). The change in the DO concentration is calculated by the change in the nitrate concentration due to the ecosystem dynamics and the air-sea exchange of oxygen at the sea surface. The variability in the biological fields do not induce feedback in the physical fields.

\section{Results}

During the observation period, seasonal thermocline, halocline, and subsurface oxygen maximum gradually are formed in the upper mixed layer, separating the subtropical mode water (STMW; Masuzawa 1969; Suga and Hanawa 1995) from the sea surface (Fig. 3a-c, and enlarged figures shown in Fig. 3d-f). Although a small semidiurnal perturbation of the internal tidal wave appears for all pressure levels on a nearly half a day cycle, the vertical pressure level and vertical gradient of the main thermocline are relatively stable. However, in 
(a)

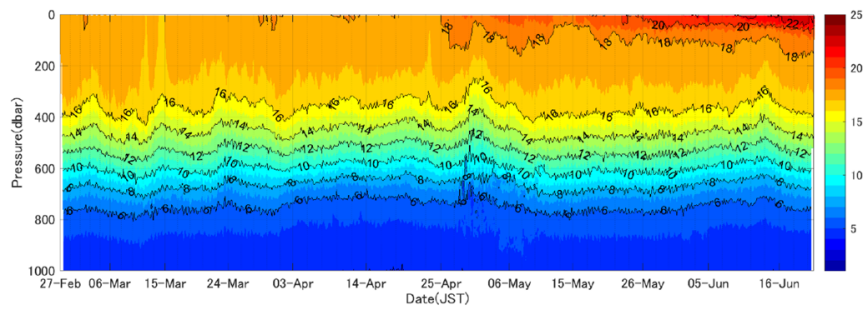

(b)

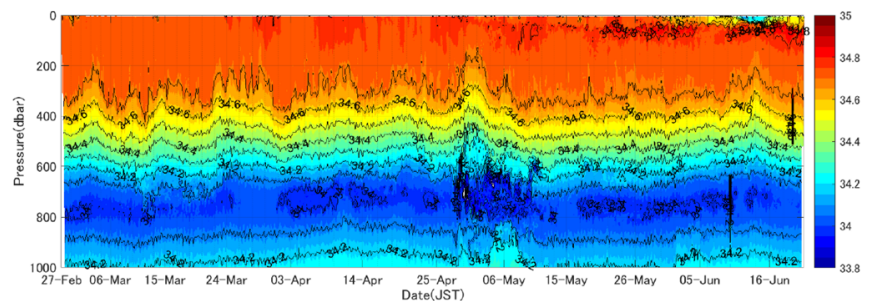

(c)

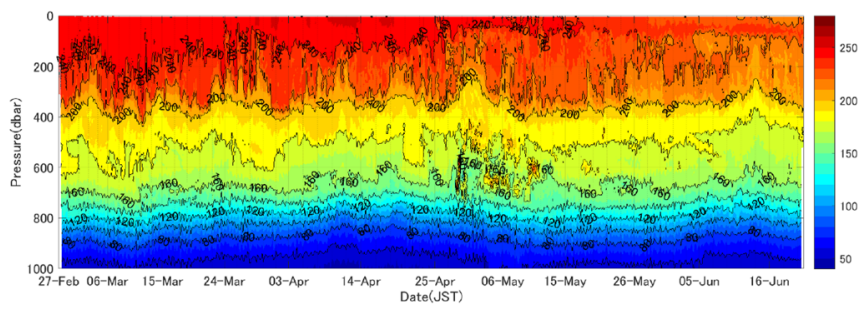

(d)

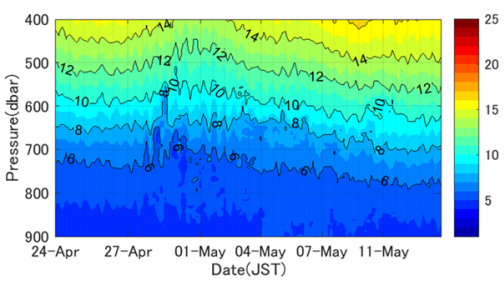

(e)

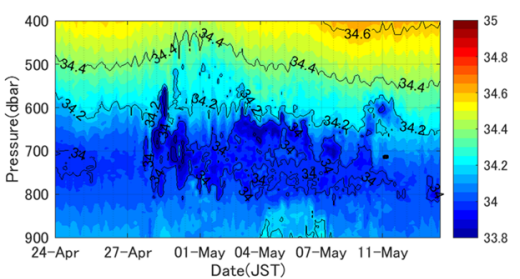

(f)

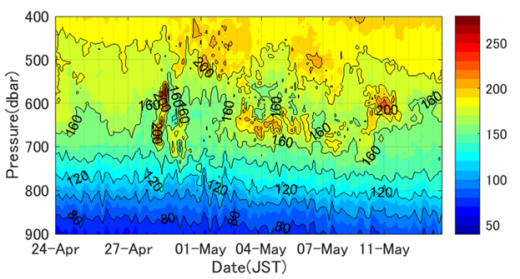

Fig. 3 Time series of a temperature $\left({ }^{\circ} \mathrm{C}\right)$, $\mathbf{b}$ salinity (PSS-78), and $\mathbf{c}$ dissolved oxygen (DO) ( $\mu \mathrm{mol} \mathrm{kg}^{-1}$ ) during the whole observation period (Feb. 27-Jun. 21, 2014) with contour intervals of $1{ }^{\circ} \mathrm{C}, 0.2$, and $20 \mu \mathrm{mol} \mathrm{kg}{ }^{-1}$, respectively. Enlarged figures of $\mathbf{d}$ temperature, e salinity, and $\mathbf{f} \mathrm{DO}$ with contour intervals of $1^{\circ} \mathrm{C}, 0.2$, and $20 \mu \mathrm{mol} \mathrm{kg}{ }^{-1}$, respectively 
the main thermocline at levels of 400-900 dbar, small perturbations are detected from late-April to mid-May. Because this study is focusing on the perturbations equivalent to small water mass parcels, our analysis highlights the details in the small water parcels for a 9day period from April 28 to May 13, 2014. In this period, Seaglider is positioned around $31.7-32.8^{\circ} \mathrm{N}, 144.5-$ $144.7^{\circ} \mathrm{E}$. This position is on the southwestern side of an anticyclonic eddy and far west (over $250 \mathrm{~km}$ ) of a cyclonic eddy detached from the KE (Fig. 1a). At the same time, the northwestward current velocity estimated by the Seaglider gradually increases and eventually reaches around $40 \mathrm{~cm} \mathrm{~s}^{-1}$ (Fig. 1b).

In the highlighted period when frequent perturbations can be seen in the main thermocline, small water parcels with temperature, salinity, and DO anomalies are observed below the winter mixed layer depth (MLD) along 26.0-27.0 $\sigma_{\theta}$ isopycnal surfaces (Fig. 4a-c), which almost corresponds to

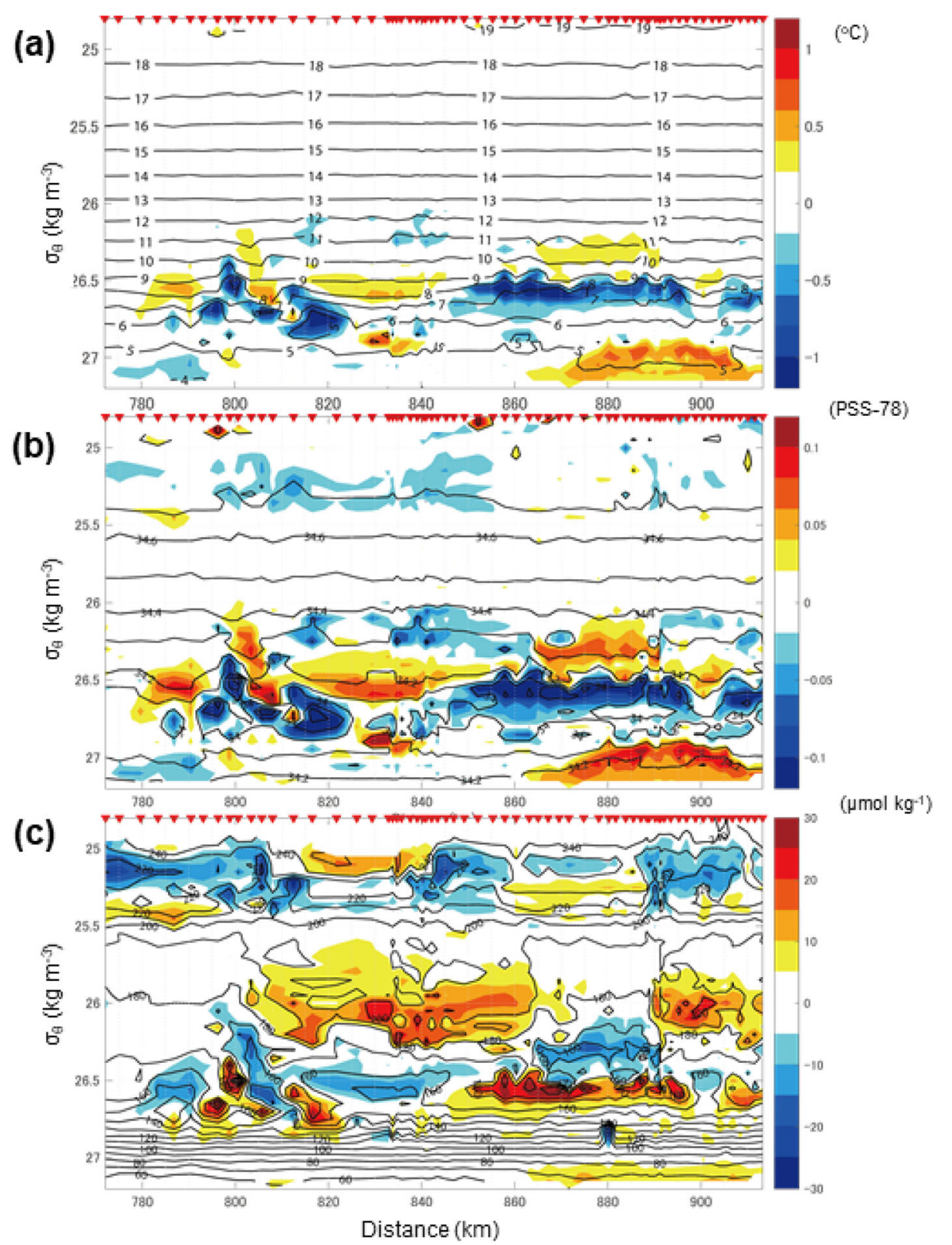

Fig. 4 Time series of a temperature $\left({ }^{\circ} \mathrm{C}\right)$, b salinity (PSS-78), and $\mathbf{c}$ DO anomaly ( $\mu \mathrm{mol} \mathrm{kg}^{-1}$; contours) on isopycnal surfaces during Apr. 28-May 13, with salinity and DO anomalies (color) calculated from the average profiles except for Apr. 28-May 13. Contour intervals of temperature, salinity, and DO are $1{ }^{\circ} \mathrm{C}, 0.1$, and $20 \mu \mathrm{mol} \mathrm{kg}{ }^{-1}$, respectively. Values on isopycnal surfaces are interpolated every $0.01 \mathrm{~kg} \mathrm{~m}^{-3}$ from the individual profiles of the Seaglider data. Linear trends calculated from the whole observation period are removed for each parameter. $x$-axis represents the cumulative distance based on the launching point 
the density ranges of the North Pacific Central Mode Water (NPCMW; 26.2-26.4 $\sigma_{\theta}$; Nakamura 1996; Suga et al. 1997) and the North Pacific Intermediate Water (NPIW; $26.8 \sigma_{\theta}$; Talley et al. 1995). In the layer below the MLD, many anomalies in temperature, salinity, and DO are detected with values of $<-0.5{ }^{\circ} \mathrm{C},-0.05$, and $>15 \mu \mathrm{mol} \mathrm{kg}{ }^{-1}$, respectively. The water parcel sizes vary significantly, that the horizontal width ranges from a few kilometers to several tens of kilometers, while the vertical thickness is mostly $0.01-0.5 \sigma_{\theta}$. Also, low (high) temperature anomalies correspond with low (high) salinity anomalies.

The high (low) DO anomalies do not always correspond with the low (high) temperature and salinity anomalies. Hence, the water parcel characteristics demonstrate that subducted water has complicated water mass properties. For example, water parcels observe around 26.7-26.9 $\sigma_{\theta}$ at a distance of $830-850 \mathrm{~km}$ along the $x$-axis have properties of low (high) temperature and salinity anomalies, but
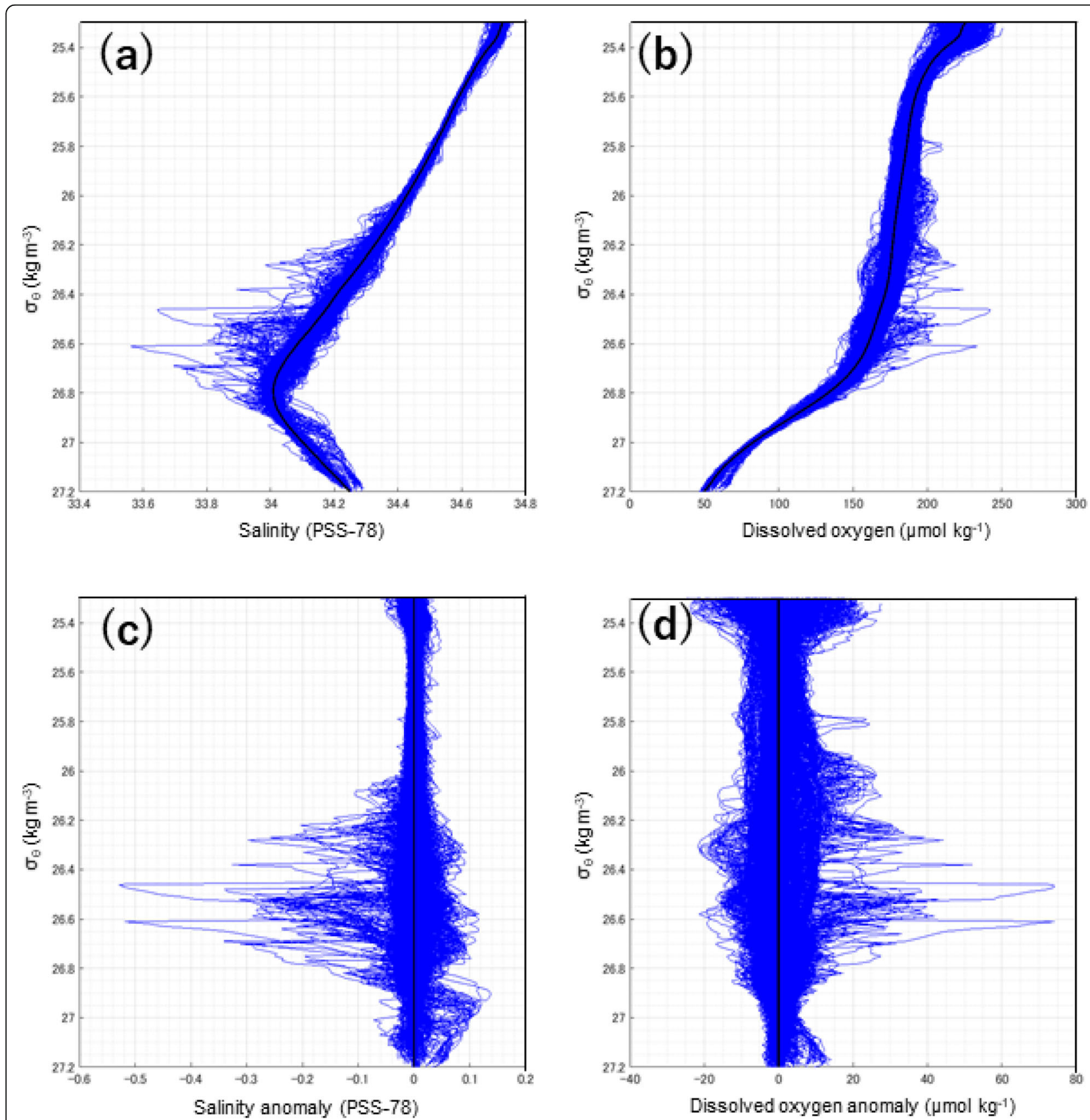

Fig. 5 Vertical profiles of a salinity (PSS-78), b DO $\left(\mu \mathrm{mol} \mathrm{kg}{ }^{-1}\right.$ ), c salinity anomaly (PSS-78), and $\mathbf{d}$ DO anomaly ( $\mu \mathrm{mol} \mathrm{kg}^{-1}$ ) on isopycnal surfaces obtained in Apr. 28-May 13. Anomalies are calculated by averaging the salinity and DO profiles through the observation period except for Apr. 28-May 13 when the period is highlighted (black solid lines) 
only low DO anomalies. On the other hand, water parcels around 26.4-26.9 $\sigma_{\theta}$ at a distance of 790-820 km have low (high) temperature, salinity, and high (low) DO anomalies.

Regarding planetary potential vorticity (f $\rho^{-1} \mathrm{~d} \rho \mathrm{dz}^{-1}$, hereafter PV), the significance of the relationship between low PV and low temperature/salinity and high DO anomalies is unclear below the main thermocline. Thus, the water parcels originate from the north of the KE where high PV water in shallow winter MLD regions is dominant (not shown here). Detecting a wide potential density range suggests that small water parcels originate in a broader area on the northern part of the KE, including levels of $>26.8 \sigma_{\theta}$ surface, which are not in contact with the winter cooling atmosphere (e.g., Talley et al. 1995; Yasuda et al. 1996).

To explore the skewness of the small water parcels in the salinity and DO profiles, Fig. 5 plots the cumulative vertical profiles in salinity, DO, and their anomalies on each isopycnal level. The vertical salinity profiles fluctuate at the mean. In particular, large negative fluctuations are observed on the isopycnal levels of 26.2-26.8 $\sigma_{\theta}$ (Fig. 5a). Vertical DO profiles have similar fluctuations to those observed in the salinity profiles, except for the large positive fluctuations on the 26.0-26.6 $\sigma_{\theta}$ (Fig. 5b). Their anomalies in salinity and DO in Fig. 5c, d indicate that the amplitudes of negative salinity (positive DO) anomalies exceeded $-0.5\left(70 \mu \mathrm{mol} \mathrm{kg}{ }^{-1}\right)$. Their histograms in Fig. 6 confirmed that the means and medians of salinity (DO) anomaly are $-0.00014\left(0.71 \mu \mathrm{mol} \mathrm{kg} \mathrm{kg}^{-1}\right)$ and $-0.018 \quad\left(1.8 \mu \mathrm{mol} \mathrm{kg}^{-1}\right)$, respectively. These represent the skewness, and the results are similar to those in $\mathrm{Li}$ et al. (2017). Hence, the characteristics of the water parcels are likely skewed with a negative salinity and positive DO in the middle and lower levels over a broad range. These also suggest that water parcels are subducted and transported from a broader range north of the KE. In contrast, such a skewness is not obvious in the upper layer (see Fig. 5). According to the vertical and horizontal resolutions of the Seaglider data, the size of each

\section{(a)}

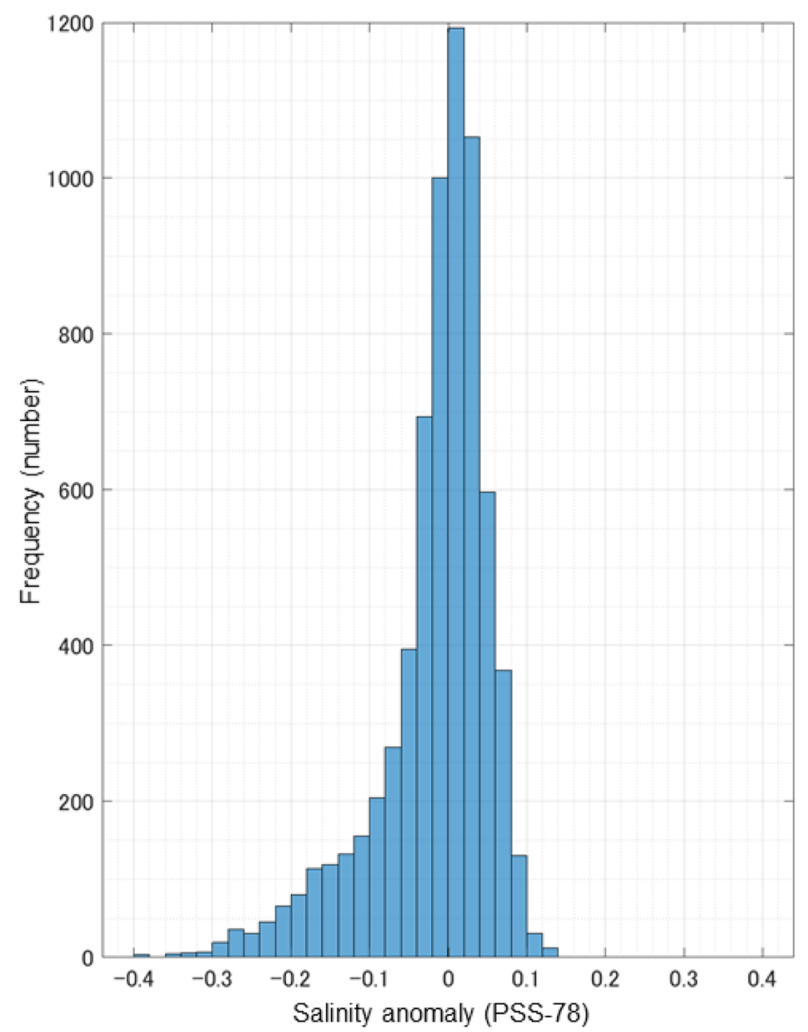

(b)

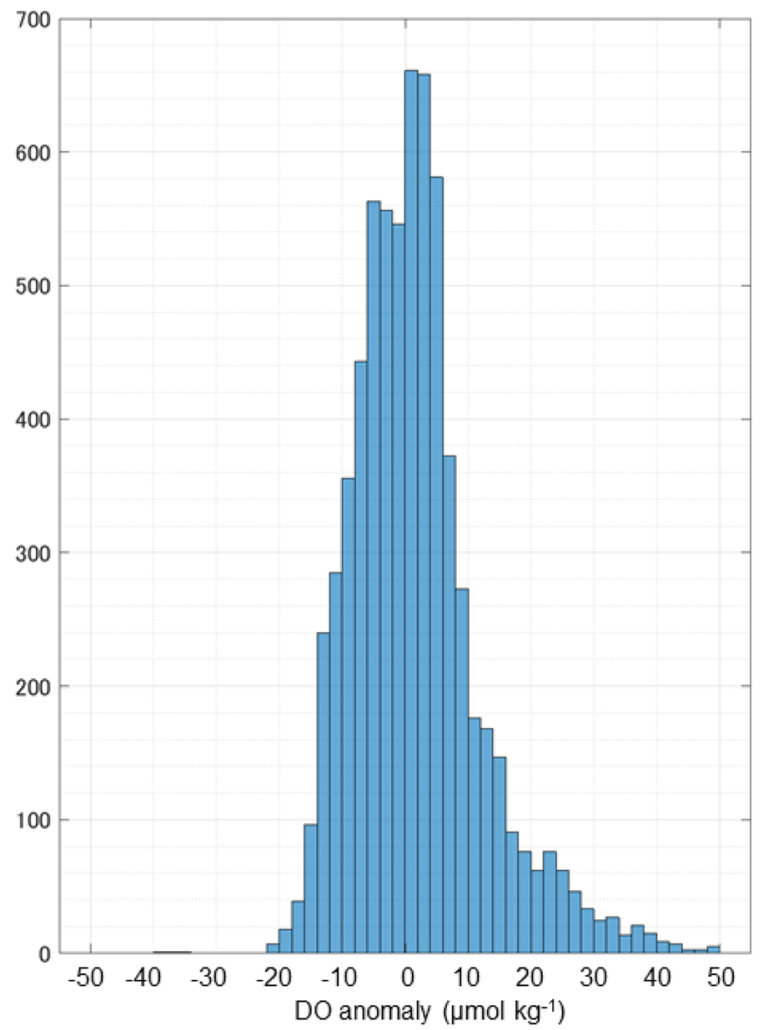

Fig. 6 Histograms in $\mathbf{a}$ the salinity anomaly (PSS-78) and $\mathbf{b}$ DO anomaly $\left(\mu \mathrm{mol} \mathrm{kg}{ }^{-1}\right.$ ) among $26.2-26.8 \sigma_{\theta}$ isopycnal levels. Frequency is counted based on the horizontally and vertically gridded data. Horizontal interval is interpolated every $1 \mathrm{~km}$, while the vertical one is every $0.01 \sigma_{\theta}$. Histograms in $\mathbf{a}$ and $\mathbf{b}$ are separated every 0.2 and $2 \mu \mathrm{mol} \mathrm{kg}{ }^{-1}$ bins, respectively. Medians of salinity and DO anomalies are -0.00014 and 0.71 , respectively. Mean salinity and DO anomalies are -0.018 and 1.8 , respectively 
water parcel varies at least $5-10 \mathrm{~km}$ in the horizontal width and 30-100 dbar in the vertical thickness. The detected spatial size indicates that the Seaglider observations can accurately measure the size of the water parcels, even below the main thermocline if using a finer sampling resolution.

Figure 7 shows the potential temperature $(\theta)-S$ diagram of the Seaglider data throughout the whole observation period along with the Argo float data in the western North Pacific Ocean observed in $25-45^{\circ} \mathrm{N}$, $140-160^{\circ} \mathrm{E}$ for January 1-April 30, 2014 for comparison. The $\theta-S$ relationship from the Argo float data shows that a wide range of water mass characteristics are existed (saltier (fresher) side of the figure is the southern (northern) part of the KE). The water mass characteristics obtained from the Seaglider are broadly detected and within the range of those from the Argo float data. Because the Seaglider collected data south of the KE in the subtropical region, the subtropical water mass characteristics are dominant and correspond to the saltier side of the $\theta-S$ diagram (orange dots). To represent the water parcels with an anomalously low salinity or a high DO water, the salinity and DO anomalies over three times the standard deviations $(3 \sigma)$ estimated from the average values through the observed period are highlighted. The characteristics of some water parcels (colored with over $3 \sigma$ of low salinity and/or high DO concentration variability) observed in $26.0-26.9 \sigma_{\theta}$ are elongated toward the fresher side of the diagram (green dots), suggesting that the water parcels may originate from the northern part of the KE (close to plots colored in green from Argo data). These observations support the skewness and the origin of the small water parcels (Figs. 5 and 6). The lower salinity of the water parcels around $3-9{ }^{\circ} \mathrm{C}$ is significant $(<34.0)$.

To clearly represent the relationship between the possible subducted area and obtained water mass characteristics, Fig. 8 maps the mean and minimum (maximum) salinity (saturated oxygen concentration) obtained from Seaglider. The saturated oxygen concentration is estimated from the in-situ temperature and salinity of Seaglider when the small water parcels are detected. Assuming that the surface sea water subducts and the water characteristics are kept without dissipation, the origin area of the small water parcels is represented as the salinity and saturated oxygen concentration from Seaglider by referring to Fig. 10 in Li et al. (2017). Using the March monthly

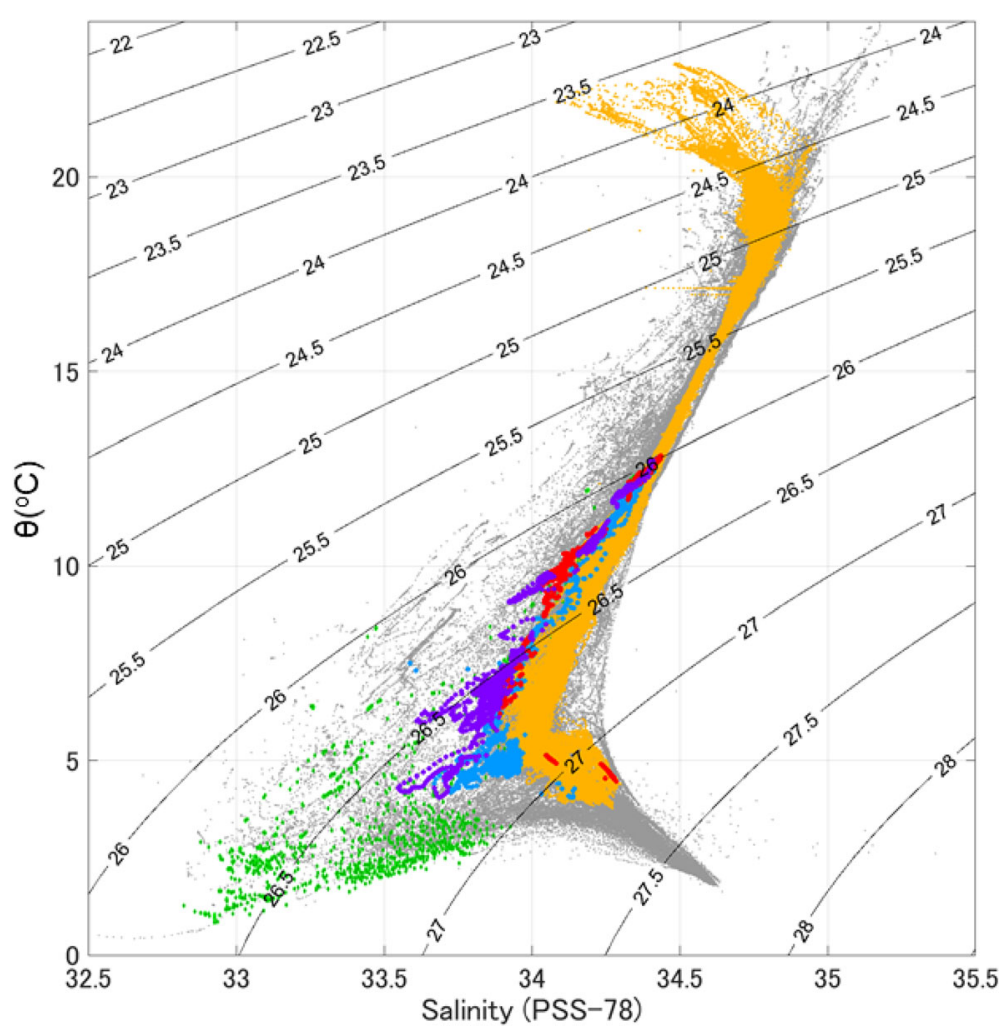

Fig. 7 -S relations of the Seaglider data with over $3 \sigma$ of negative salinity anomaly (blue circles), positive DO anomaly (red circles), and both (purple circles) during Apr. 28-May 7, 2014. Orange dots represent all Seaglider data for Feb. 27-Jun. 21. Background gray dots show Argo data observed in $25-45^{\circ} \mathrm{N}, 140-160^{\circ} \mathrm{E}$ for Jan. 1-Apr. 30, 2014. Green dots are the same Argo data but observed in the upper subpolar region above $300 \mathrm{dbar}$ at $41-45^{\circ} \mathrm{N}, 142-160^{\circ} \mathrm{E}$ 


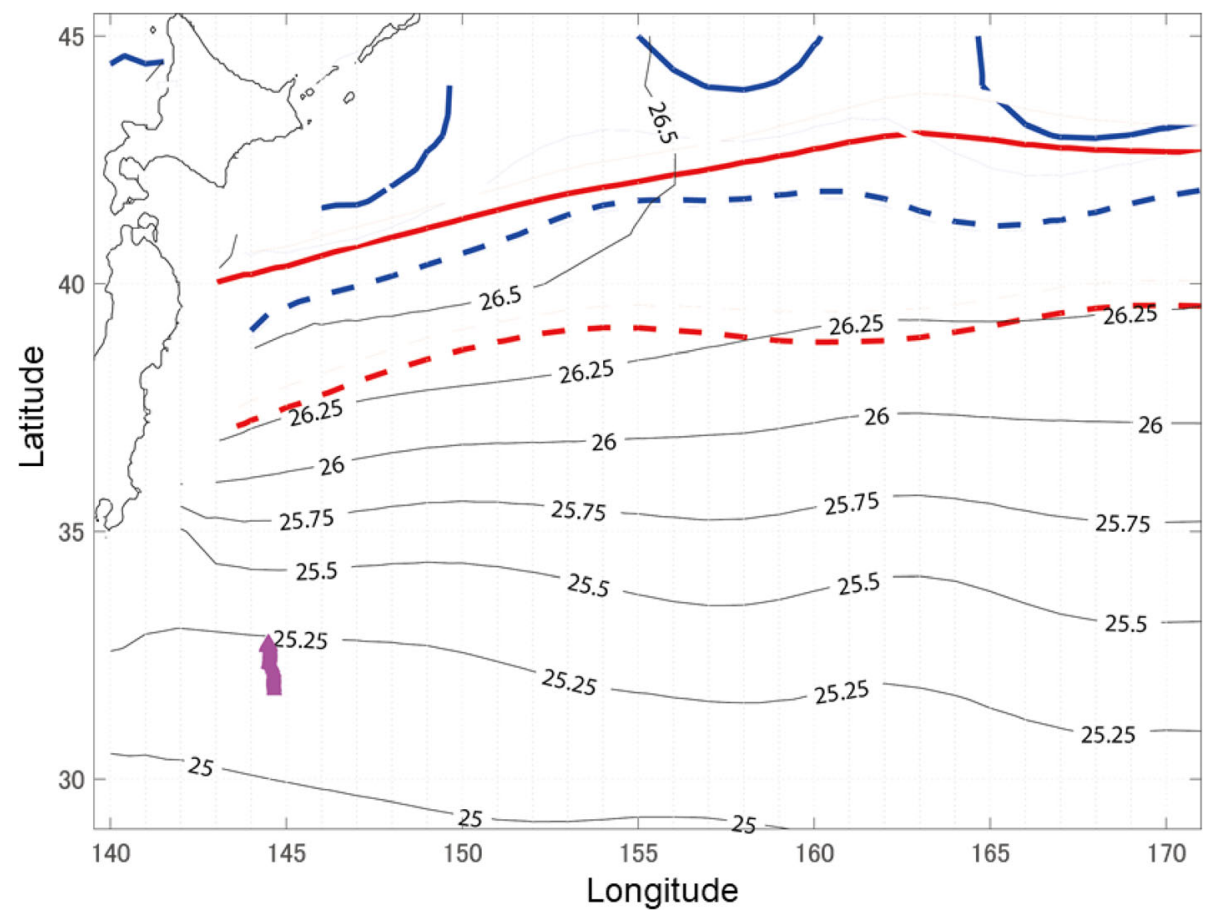

Fig. 8 Red dashed (solid) and blue dashed (solid) lines show surface (50 m depth) mean (minimum) salinity and mean (maximum) saturated oxygen concentration detected in the Seaglider data, respectively, based on March averaged data in the WOA18. Black contours show the outcrop lines of the corresponding isopycnal surfaces. Magenta dots are the Seaglider position during the period when small water parcels are detected

$\mathrm{T}, \mathrm{S}$, and DO climatologies in the World Ocean Atlas 2018 (Locarnini et al. 2018; Garcia et al. 2018; Zweng et al. 2018) when the MLD is deepest, the blue solid (dashed) and red solid (dashed) lines in Fig. 8 show the mean (minimum) salinity and mean (maximum) saturated oxygen concentration of the small water parcels detected in Seaglider, respectively. Apparently, the salinity and saturated oxygen concentration distribution locate in the north of KE, which suggests that the small water parcels are advected southward across the KE.

Figure 9 shows the $\sigma_{\theta}-\mathrm{S}$ diagram of the Seaglider data using the same color scheme as that in Fig. 7. The water parcels along 26.2, 26.5, and $26.7 \sigma_{\theta}$ displayed low salinity characteristics, corresponding to minimum salinity values of $33.8,33.6$, and 33.5 , respectively. The low salinity properties extend on the isopycnal surfaces, indicating that the small water parcels occasionally intrude at arbitral isopycnal surfaces. Figure 10 shows the $\sigma_{\theta}-\mathrm{DO}$ diagram of the Seaglider data using the same color scheme as in Figs. 7 and 9. In 26.2-26.7 $\sigma_{\theta}$ isopycnal surfaces, the DO concentration is basically within $150-200 \mu \mathrm{mol} \mathrm{kg}{ }^{-1}$, while a high DO water over $200 \mu \mathrm{mol} \mathrm{kg}{ }^{-1}$ is detected within the 26.2-26.7 $\sigma_{\theta}$ isopycnal surfaces, which has a maximum of $250 \mu \mathrm{mol} \mathrm{kg} \mathrm{g}^{-1}$. However, a high DO water does not correspond well with the low salinity water shown in Figs. 9 and 10. In addition, the high DO value below $26.7 \sigma_{\theta}$ is unclear, indicating that higher DO water tends to be distributed in the upper layer relative to the lower salinity water in the lower layer. Figures 9 and 10 indicate that the $\sigma_{\theta}$ level appearing in low salinity water differs slightly from that of high DO water, suggesting that the origin and characteristic of subducted water parcels at the sea surface north of the KE differ from each other.

Based on the in situ DO, temperature, and salinity values, the apparent oxygen utility (AOU) and saturated oxygen concentration are calculated. Hence, the relative residence time of water parcels is estimated since subducted sea water from the sea surface is saturated with oxygen by contacting the atmosphere. Figure 11 shows $\sigma_{\theta}-\mathrm{AOU}$ diagram from the Seaglider data. Note that small water parcels with larger negative salinity anomalies and positive DO anomalies locate below the euphotic zone (here, we assume the euphotic zone is above $100 \mathrm{~m}$ by referencing Ryther 1956; Lee et al. 2007). We estimate AOU to show the amount of oxygen consumption relative to the elapsed time to advect from the sea surface because a comparison of the relative elapsed time differences among the small water parcels provides information about whether the water is relatively young by its ratio. Here, a low AOU means nearly saturated 


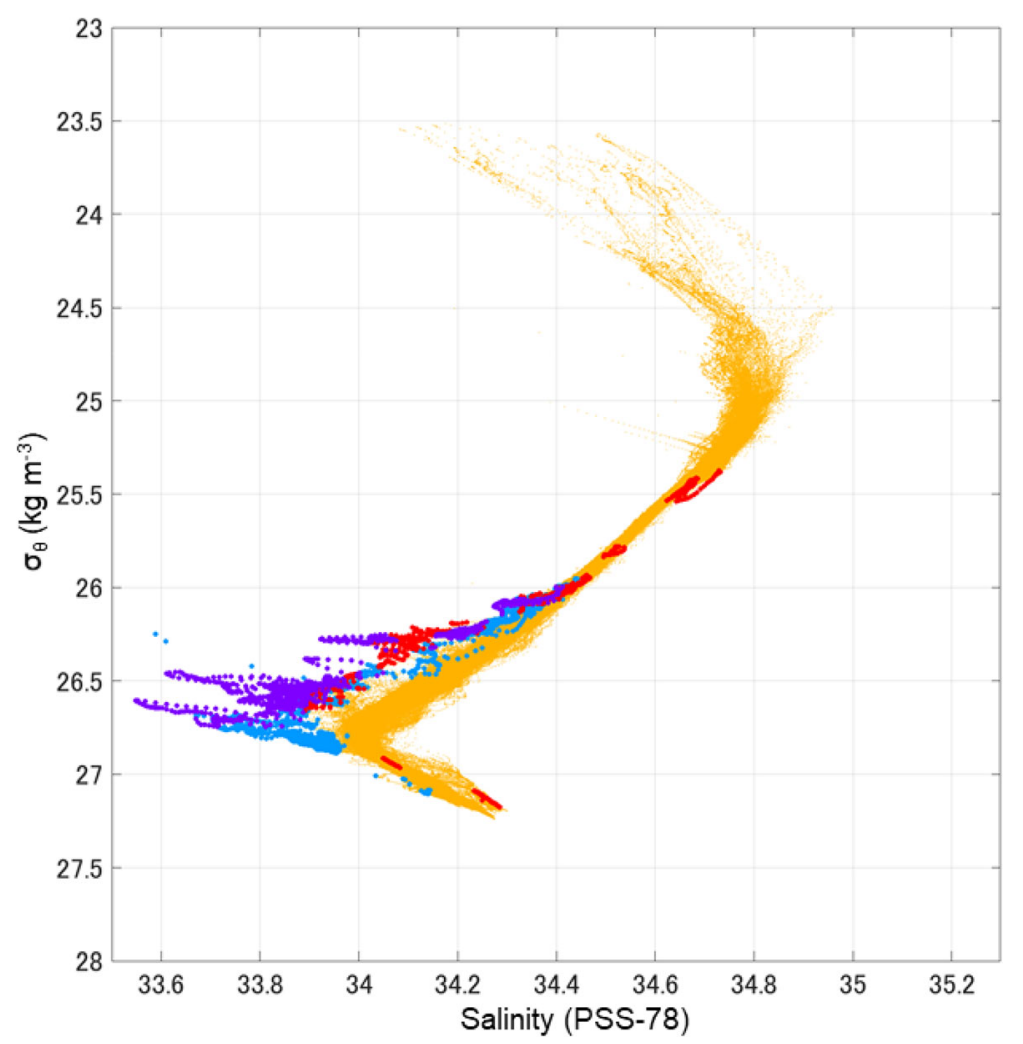

Fig. $9 \sigma_{\theta}-S$ diagram of the Seaglider data, colored with over $3 \sigma$ of negative salinity anomaly (blue circles), positive DO anomaly (red circles), and both (purple circles) below 400 dbar during Apr. 28-May 13. Orange dots represent all Seaglider data for Feb. 27-Jun. 21

oxygen water, which occurs closer to the surface, while a high value indicates far away from the sea surface. Assuming the water parcels move with time along a $\sigma_{\theta}$ surface after subduction, the age of a water parcel to the surrounding water mass is estimated by comparing the AOU. At a few $\sigma_{\theta}$ surfaces where water parcels with over $3 \sigma$ of DO and/or salinity anomalies are detected, the AOU of $45-80 \mu \mathrm{mol} \mathrm{kg} \mathrm{kg}^{-1}$ on $26.2-26.8 \sigma_{\theta}$ is observed, while those in the surrounding water are $75-130 \mu \mathrm{mol}$ $\mathrm{kg}^{-1}$, respectively. Assuming that the water parcels are advected with only some diffusive processes after subduction and that the water is unaffected by the other processes to control the DO concentration, the water parcels with a high DO and low salinity should be about $30-60 \%$ younger than the surrounding water on the same $\sigma_{\theta}$. Although the estimated elapsed time cannot provide an accurate time to advect from the sea surface, a comparison of the relative elapsed time differences among the small water parcels can provide information about whether the water is relatively young by assuming a constant oxygen consumption rate below the sea surface. In the next section, we will discuss the age of water parcels as well as the possibilities to detect younger water parcels using the high-resolution numerical model OFES.

\section{Discussion}

Based on the water mass analyses, we assume that fresher and higher DO water parcels advect across the KE from the northern part. How do these parcels arrive in the south KE below the main thermocline while maintaining low salinity and high DO properties? Generally, there are three possibilities to explain the DO concentration variation (Fig. 11). (1) Strong vertical mixing adds high DO and low salinity water during advection (e.g., Yoshikawa et al. 2001, 2012). (2) Oversaturated DO water is subducted below the sea surface and advected across the KE (e.g., Miyake and Saruhashi 1966). (3) The water at the sea surface subducts at the north of the KE, and then advects faster across the KE. Since the water parcels are detected below $600 \mathrm{dbar}$ and higher DO concentrations are observed from those water characteristics, herein we consider hypothesis (3) to be more appropriate.

Regarding the possibility of item (3), we examine whether the water parcels advect quickly across the $\mathrm{KE}$ without losing properties using the output of the $1 / 30^{\circ}$ fine-resolution OFES model. In the longitude-depth sections of the salinity snapshot on May 15, 2003 (Fig. 12, top-left panel), low salinity water parcels $(<33.8)$ appear in $142-150^{\circ} \mathrm{E}$ and in $26.4-26.8 \sigma_{\theta}$. From the salinity 


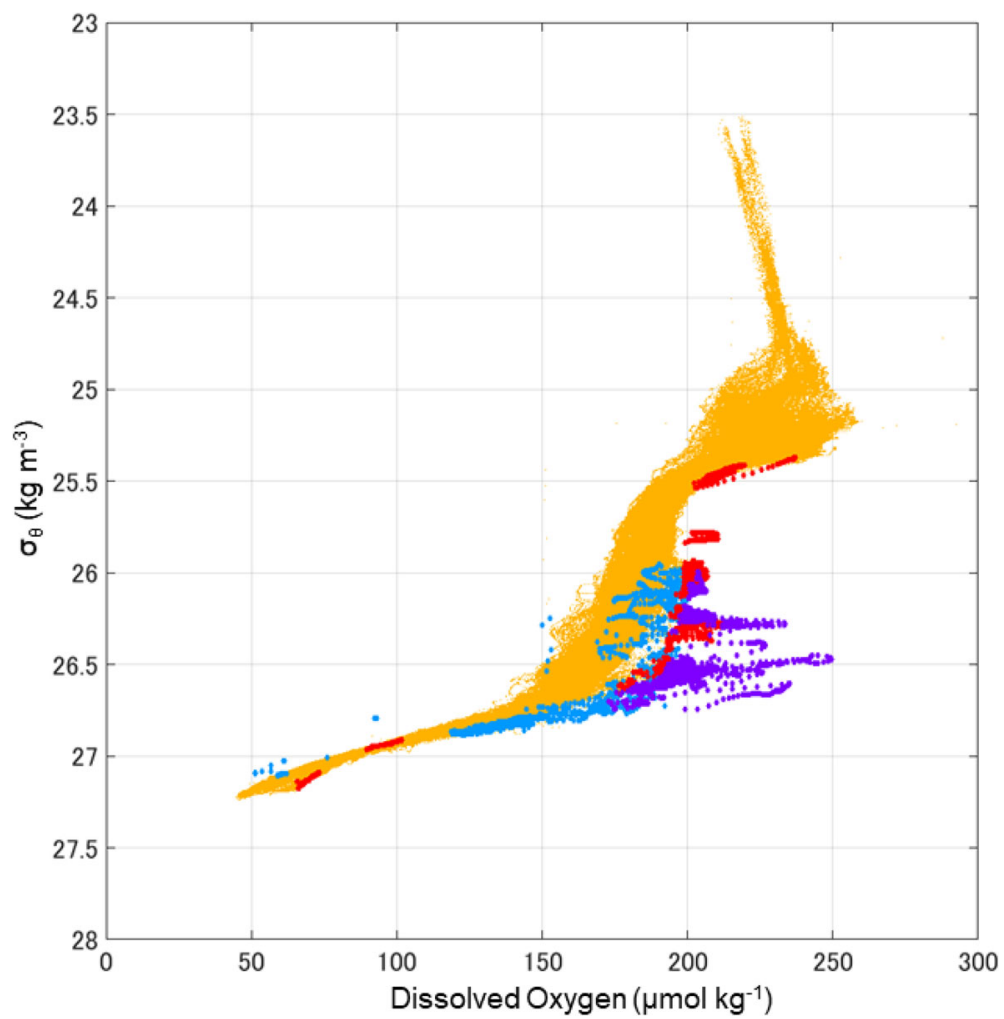

Fig. 10 Same as Fig. 8 except for the $\sigma_{\theta}-D O$ diagram of the Seaglider data, which is colored with over $3 \sigma$ of negative salinity anomaly (blue circles), positive DO anomaly (red circles), and both (purple circles)

maps on the isopycnal surfaces, the extremely low salinity water $(<33.6)$ off east Japan $\left(38^{\circ} \mathrm{N}, 142^{\circ} \mathrm{E}\right)$ on April 5 expand southeastward, drifting with the southward flow on the edge of the cyclonic mesoscale eddy around $34^{\circ} \mathrm{N} 146^{\circ} \mathrm{E}$ from April 15 to 25 (Fig. 12). On April 30, a thin elongated filament-like water parcel with a low salinity $(<33.7)$ expand to the west around the south of the mesoscale eddy. The elongated filament is pulled by the neighboring anticyclonic eddy at the center of $33^{\circ} \mathrm{N}$ $143^{\circ} \mathrm{E}$, arriving south of the eddy on May 10-15. The low salinity water parcels shown in the zonal section correspond to the low salinity filaments on the isopycnal salinity map on May 15.

Figure 13 shows a similar zonal section snapshot and isopycnal distribution of DO in the OFES output for the shallower layer $\left(26.4-26.6 \sigma_{\theta}\right)$ than in the case of salinity. The higher DO water parcels $\left(>200 \mu \mathrm{mol} \mathrm{kg}^{-} 1\right)$ appear off east Japan around $37^{\circ} \mathrm{N} 143^{\circ} \mathrm{E}$. These are advected to the southeast similar to the salinity map around April 15. Finally, the high DO water parcels approach south of the anticyclonic eddy at $33^{\circ} \mathrm{N} 143^{\circ} \mathrm{E}$ to the west of the cyclonic eddy at $34^{\circ} \mathrm{N} 146^{\circ} \mathrm{E}$. The high DO water parcels shown in the DO zonal section also correspond with high DO filaments elongated westward in the isopycnal map on May 15. A comparison of Figs. 12 and 13 suggests that the high DO and the low salinity filaments correspond well with those detected by the Seaglider observation in the upper (600-800 dbar) and lower (700-900 dbar) layers, respectively.

This suggests that the properties of water parcels displayed in the OFES data correspond well with those in the Seaglider data. In addition, the horizontal snapshots of the DO and salinity on 26.5 and $26.7 \sigma_{\theta}$ indicate a rapid advection process from the subpolar region to the subtropical region across the KE, which is largely associated with mesoscale eddies. Surprisingly, the time passed from off northern Japan to the south of the KE is less than 1 month in the OFES analysis. Compared to previous studies, which assumes the subduction process occurs in a wider area, this is quite short. For similarly small water parcels observed just south of the KE from mooring data, Nagano et al. (2016) estimated its age as about a half year, which was also shorter than the water age based on the traditional subduction theory (Luyten et al. 1983).

To investigate the importance of the small water parcels across the KE, we estimate the appearance rate of low salinity $(<33.8)$ in the daily mean high resolution OFES data, which is counted on $26.7 \sigma_{\theta}$ through the 2003 model year. The appearance rate distribution of low salinity on $26.7 \sigma_{\theta}$ displays a high rate $(\sim 1.0)$ around the northern part of the map but gradually decreases to 


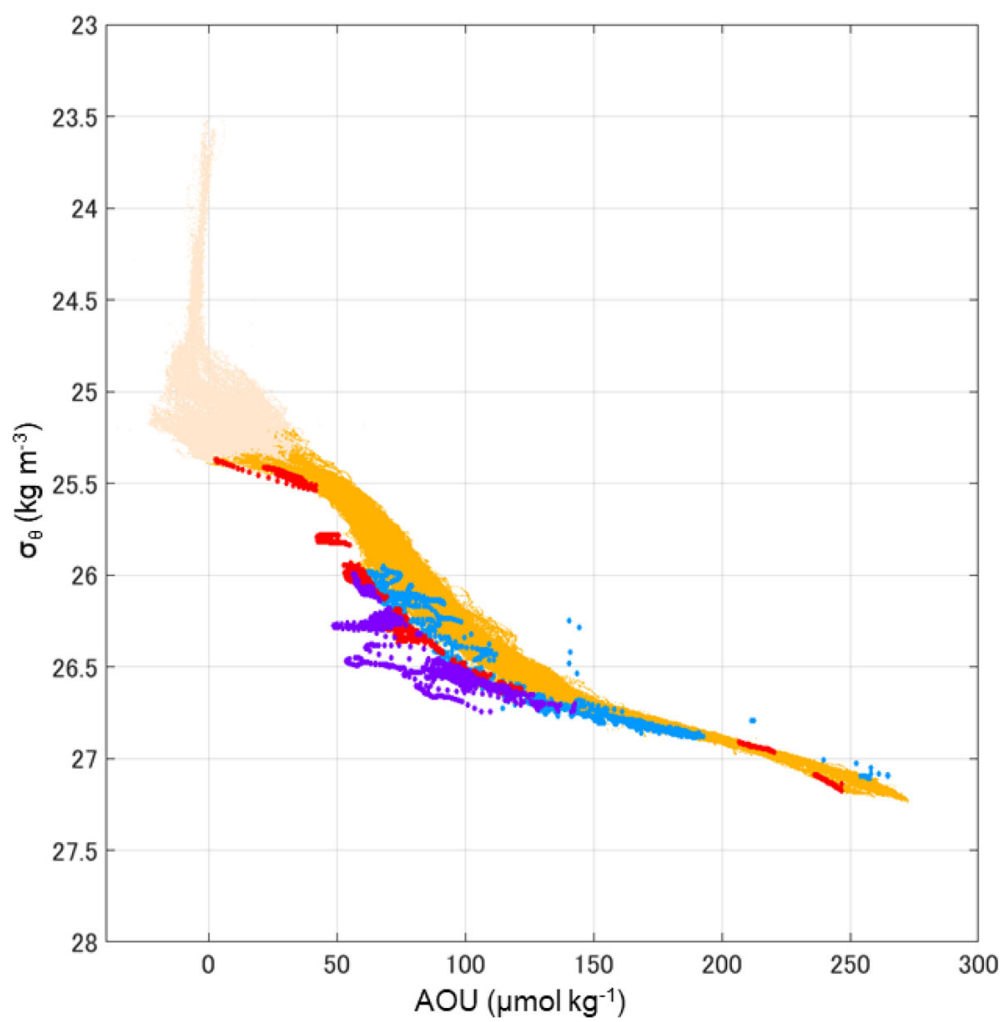

Fig. 11 Same as Figs. 9 and 10, except for $\sigma_{\theta}$-AOU diagram, colored with over $3 \sigma$ of negative salinity anomaly (blue circles), positive DO anomaly (red circles), and both (purples). AOU is calculated by Cs-DO. Light orange indicates DO measurements in the euphotic zone

the south (Fig. 14a). However, a tongue-like higher frequency rate $(>0.3)$ extends around $34^{\circ} \mathrm{N} 145^{\circ} \mathrm{E}$ and to the south, which is near where the small water parcels are captured in the high-resolution OFES and Seaglider. Figure 14b shows a zonal section of the frequency rate along $34^{\circ} \mathrm{N}$ to identify the density level of the higher appearance rate. The peak rate occurred around $145^{\circ} \mathrm{E}$, $26.7 \sigma_{\theta}$, indicating that the small water parcels are elongated as a filament structure and tend to appear around the layers where Seaglider observed the low salinity parcels. Because the analysis is performed only for 1 year which may not be long enough to represent an appropriate frequency rate distribution including influences of oceanic variability, further investigations are required to understand why the small water parcels tend to be detected around there and its interannual variability. Meanwhile, the small water parcels across the KE are frequently exchanged in the southeast of Japan, suggesting the importance of the small water parcels to transport heat, freshwater, and materials as well as the modification processes of water mass.

As mentioned in the introduction, a similar small water mass has been observed by ship and float observations. Previous papers described this as "subthermocline eddies," "Kiddies," or "SCVs." Herein, we use the term "small water parcels" instead of these other terms because we cannot find a low PV core or any eddy elements from the Seaglider data. Therefore, we are unable identify whether the small water parcels are the same as those shown in previous studies. The reason for the difference between our study and the previous ones might be the lack of vertical measurement resolutions (here, every 30 dbar below 600 dbar) relative to the vertical size of the small water parcels.

One possible exception is the water mass observed by Nagano et al. (2016). They detected subsurface intrusions of water parcels with a low salinity and high DO water around a 400-900 m depth based on high accuracy data from mooring and ship observations. Although the observed area of the small water parcels was a little more north around $34^{\circ} \mathrm{N}$ and closer to the KE, the water mass appeared to be similar to ours except for the detection of low PV. They suggested that the detected small water mass subducted from the north, came across the KE, and was elongated horizontally from mesoscale eddies. Our suggested origin of the small water parcels is supported by those by Nagano et al. These previous results also indicated that such small-scale phenomena must appear in the main thermocline frequently. 


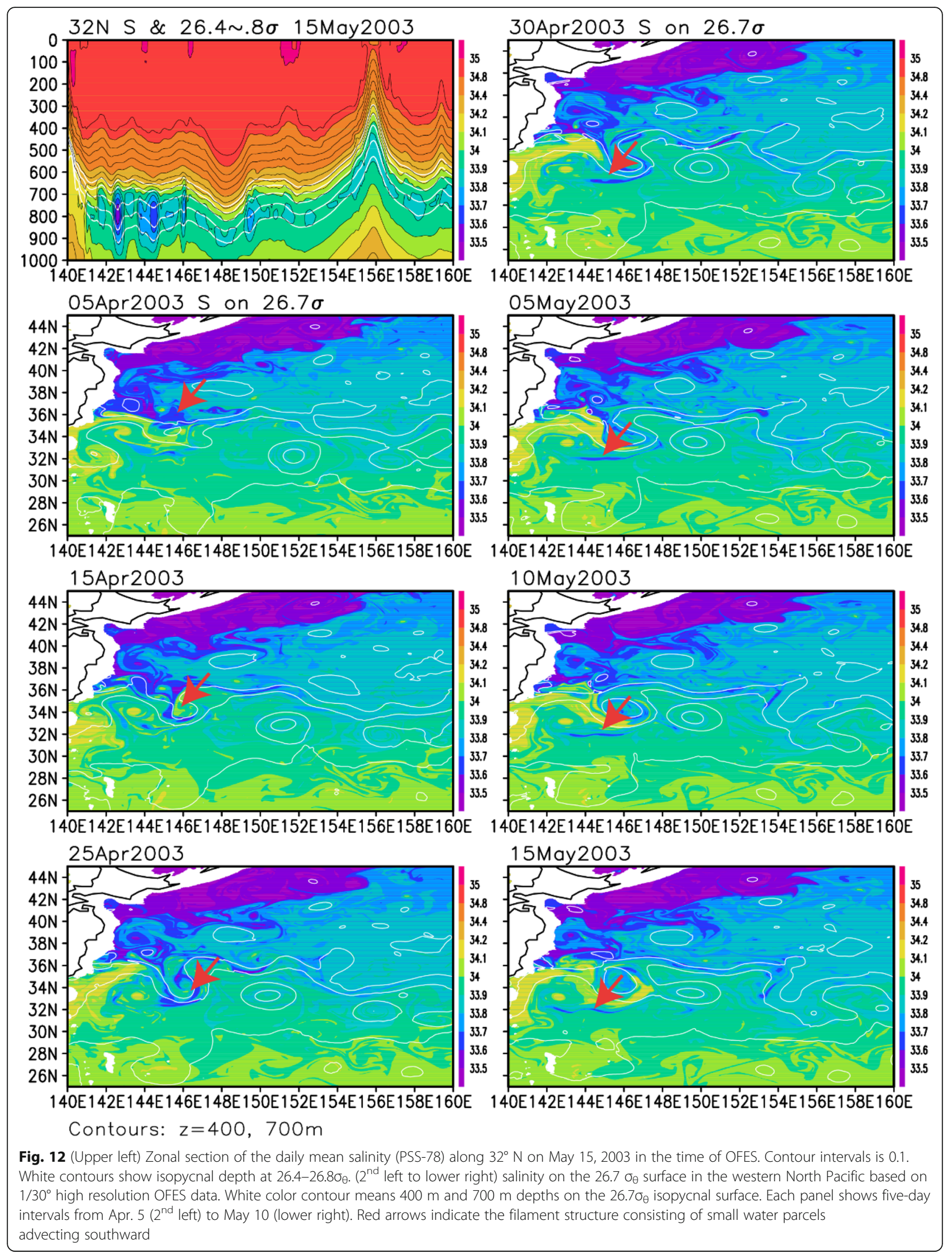




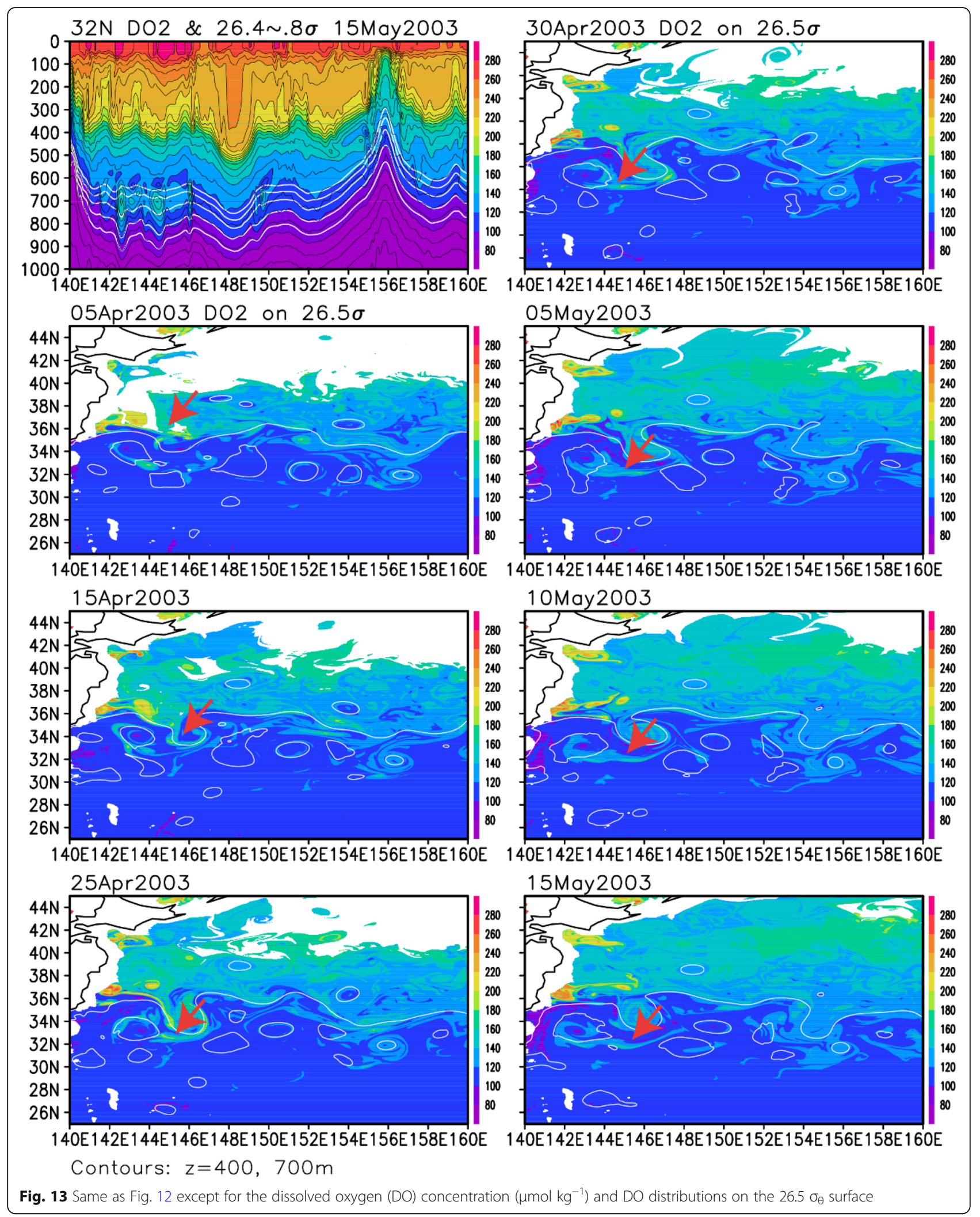




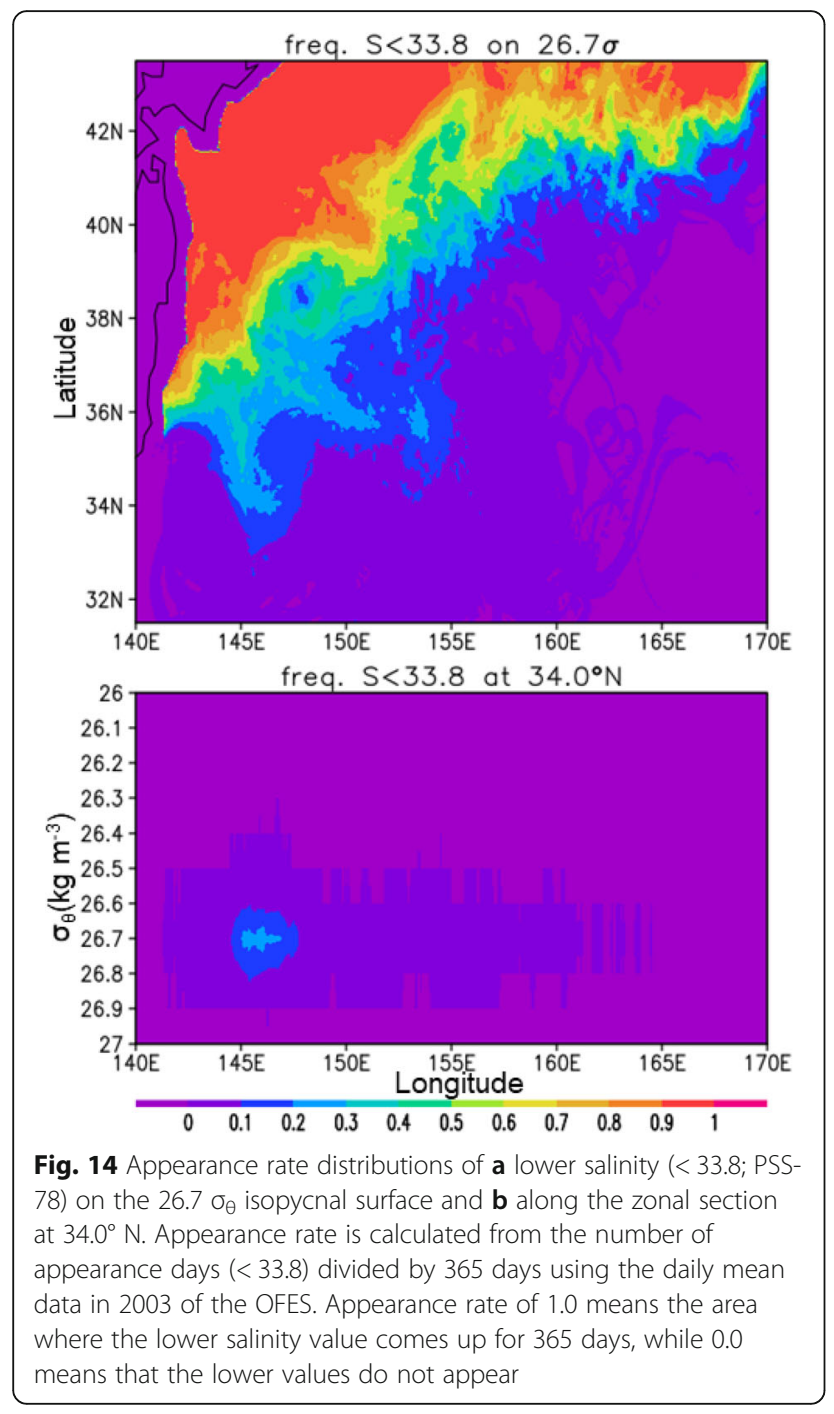

Then what is the difference in the size, appearance depth, and water properties among previous research and ours? Besides the lack of observed vertical resolution, the difference in the appearance of small water parcels may originate from the differences of the water properties, MLD, and spatial scale of formed water parcels. Figures 12 and 13 show that the salinity and DO concentrations at the sea surface are complexly distributed with meso- and submesoscale phenomena. The observed water mass characteristics of temperature, salinity, and DO anomalies in the subsurface layer with variable time and spatial scales shown in Fig. 4 may reflect the complex distribution of the water characteristics at the sea surface. Although the water parcels obtained by high-resolution OFES agree well with the origin and the propagation path qualitatively, considering the scales of the observed water parcels, the model resolution is insufficient to show detailed influences of the meso- and submesoscale processes. Besides, the
Seaglider measurement of the vertical and horizontal direction in this study is not enough to detect the accurate size of the water parcels, especially the vertical resolution in the subsurface layer. Therefore, to investigate a more detailed mechanism and water characteristics with the biogeochemical process, analyses with finer temporal and spatial scales are required using Seaglider observations and finer resolution numerical models. Such investigations will clarify the characteristics and mechanisms of small water parcels and the exchange process across oceanic fronts shown by this study.

\section{Summary and conclusion}

Seaglider was operated south of the KE from late winter to early summer in 2014. Small water parcels with a high DO and low salinity on 26.0-27.0 $\sigma_{\theta}$ were observed for 2 weeks in the spring season. At the southwestern side of an anticyclonic eddy just south of the KE, small water parcels with variable spatial sizes are detected with spatial scales of several to a few tens of kilometers. The DO concentration of the water parcels is larger than $150 \mu \mathrm{mol} \mathrm{kg} \mathrm{kg}^{-1}$ and the salinity is lower than 34.0. Although water parcels with a low salinity on $26.4-26.7 \sigma_{\theta}$ are detected without low PV, the high DO on $26.2 \sigma_{\theta}$ is similar to the water parcels described in previous studies. Our water mass analysis using the $\theta-S$ diagram show the water parcels observed by Seaglider originated from the north and are advected across the KE. The rates of low salinity and high DO water parcels depend on the depth. A high DO water tends to appear in the upper layer, whereas low salinity water is more often present in the lower layer. Based on DO and AOU analyses, the low salinity and high DO water are relatively younger by about $30-60 \%$ than the surrounding water in the subtropical region, assuming that the water is unaffected by other processes that control the DO concentration on the same $\sigma_{\theta}$ surfaces. These results successfully detect detailed characteristics of water parcels in the subsurface layer with finer spatial resolution observations.

Using a fine horizontal resolution numerical model OFES, similar water parcels are detected in the main thermocline just south of the KE. The trace path of the water parcels originates from east Japan, indicating that the anomalies of salinity and DO depend on the density range and origin. Additionally, meso- and submesoscale phenomena associated with the mesoscale activity affect the advection from the north to the south of the KE. In other words, the water may be transported across the KE by mesoscale eddies and filaments in the main thermocline. Further observations and quantitative analyses using fine resolution observational and numerical models are crucial to clarify the mechanism of advection 
and the amount of transportation. Our study demonstrates that additional information about water mass exchange can be obtained using integrated physical and biogeochemical processes and quantifying the migration of the small water parcels in the western part of the Pacific basin.

\section{Abbreviations \\ AOU: Apparent oxygen utility; BGC: Biogeochemical; CTD: Conductivity temperature depth device; DO: Dissolved oxygen; GDAC: Global Argo data assembly center; KE: Kuroshio Extension; MLD: Mixed layer depth; MOM: Modular ocean model; MWR: Mixed water region; NPCMW: North Pacific Central Mode Water; NPIW: North Pacific Intermediate Water; NPZD: Nutrient-phytoplankton-zooplankton-detritus; PV: Potential vorticity; SSHA: Sea surface height anomaly; STMW: Subtropical mode water; OFES: Ocean general circulation model For the Earth Simulator; TRMW: Transition mode water}

\section{Acknowledgments}

First, we thank the two anonymous reviewers for their encouragement and useful comments. We are grateful Dr. K. Toyama and Dr. K. Sato for their support of the Seaglider operations and JAMSTEC's Argo data management team for observations and data management. Regarding the deployment and recovery of the Seaglider, we thank Dr. K. Kutsuwada and Dr. Y. Kawai as the principal investigators and the crews of the Hakuho-Maru (KH14-1) and Kaiyo (KY14-9) for their great efforts in planning and implement the observations. We also thank Dr. Fujiki for the useful advice in response to the reviewers. The high-resolution OFES dataset was conducted using the Earth Simulator with the support of JAMSTEC. We thank the National Center for Atmospheric Research Staff (Eds) for their assistance in obtaining the sea surface height anomalies. Last modified July 1, 2016. "The Climate Data Guide: AVISO: Satellite-derived Sea Surface Height above Geoid." Retrieved from https://climatedataguide.ucar.edu/climate-data/aviso-satellite-derived-seasurface-height-above-geoid. "The Argo float data were collected and made freely available by the International Argo Program and the national programs that contribute to it (http://www.argo.ucsd.edu, http://argo.jcommops.org). The Argo Program is part of the Global Ocean Observing System." This work was supported by the Japan Society of Promotion of Science (JSPS) through Grants-in-Aid for Scientific Research in Innovative Areas 2205 and the Ministry of Education, Culture, Sports, Science and Technology (MEXT) of Japan through Grants-in-Aid for Scientific Research on Innovative Areas (JP19H05700, JP19H05701).

\section{Authors' contributions}

$\mathrm{SH}$ proposed the topic, conceived, and designed the study. RI organized the Seaglider observations and collaborated in the study. MN conducted the experimental analysis using high-resolution OFES. HS created the highresolution OFES data and supported the analysis. YS organized the NPZDC model for the OFES and supported the analyses. MH supported the Seaglider observations and resolved hardware issues regarding the operation. All authors read and approved the final manuscript.

\section{Funding}

This work was supported by the Japan Society of Promotion of Science (JSPS) through Grants-in-Aid for Scientific Research in Innovative Areas 2205 and the Ministry of Education, Culture, Sports, Science and Technology (MEXT) of Japan through Grants-in-Aid for Scientific Research on Innovative Areas (JP19H05700, JP19H5701).

\section{Availability of data and materials}

Seaglider: The Seaglider dataset is available from the corresponding author upon reasonable request, including profile and technical data. The data inventory is also available in the summary report of Hakuho-Maru cruise (KH14-1; in Japanese) https://ocg.aori.u-tokyo.ac.jp/member/eoka/cruises/ kh-14-1/report/KH-14-1 report.pdf.

Argo float data: The Argo profile data, which was compared with the Seaglider data, is available from the GDAC sites described in detail: Argo (2019) Argo float data and metadata from Global Data Assembly Centre (Argo GDAC). SEANOE. https://doi.org/10.17882/42182.
High-resolution OFES: The $1 / 30^{\circ}$ OFES simulation datasets analyzed during this study are not publicly available due to the huge size of the daily data but are available upon reasonable request.

AVISO SSHA: The dataset used to explain the background environment in this study is available in the AVISO SSHA https://climatedataguide.ucar.edu/ climate-data/aviso-satellite-derived-sea-surface-height-above-geoid.

Shipboard CTD cast: The CTD cast data of Hakuho-Maru cruise (KH14-1) and Kaiyo (KY14-9) for the Seaglider data calibration are available as inventories in https://ocg.aori.u-tokyo.ac.jp/member/eoka/cruises/kh-14-1/report/KH-14-1 report.pdf. and http://www.godac.jamstec.go.jp/catalog/doc_catalog/ metadataDisp/KY14-09_all?lang=en, respectively.

\section{Competing interests}

The authors declare that they have no competing interests.

\section{Author details}

${ }^{1}$ Research Institute for Global Change, Japan Agency for Marine-Earth Science and Technology, 2-15 Natsushima-cho, Yokosuka, Kanagawa 237-0061, Japan. ${ }^{2}$ Research Institute for Value-Added-Information Generation, Japan Agency for Marine-Earth Science and Technology, 2-15

Natsushima-cho, Yokosuka, Kanagawa 237-0061, Japan.

Received: 14 July 2020 Accepted: 8 January 2021

Published online: 03 February 2021

\section{References}

Akima H (1970) A new method for interpolation and smooth curve fitting based on local procedures. J Assoc Comput Mech 17:589-603

Argo (2000) Argo float data and metadata from Global Data Assembly Centre (Argo GDAC). SEANOE. https://doi.org/10.17882/42182

Argo (2020) Argo float data and metadata from Global Data Assembly Centre (Argo GDAC). SEANOE. https://doi.org/10.17882/42182

Bower AS, Hendry RM, Amrhein DE Lilly JM (2013) Direct observations of formation and propagation of subpolar eddies into the subtropical North Atlantic. Deep Sea Res Part II 85:15-41. https://doi.org/10.1016/j.dsr2.2012.07. 029

Eriksen CC, Osse TJ, Light RD, Wen T, Lehman TW, Sabin PL, Ballard JW, Chiodi AM (2001) Seaglider: a long-range autonomous underwater vehicle for oceanographic research. IEEE J Ocean Eng 26(4):424-436

Garcia HE, Weathers K, Paver CR, Smolyar I, Boyer TP, Locarnini RA, Zweng MM, Mishonov AV, Baranova OK, Seidov D, Reagan JR (2018) World Ocean Atlas 2018, Volume 3: Dissolved oxygen, apparent oxygen utilization, and oxygen saturation, A. Mishonov Technical Ed.; NOAA Atlas NESDIS 83, p 38

Inoue R, Faure V, Kouketsu S (2016b) Float observations of an anticyclonic eddy off Hokkaido. J Geophys Res Oceans 121:6103-6120. https://doi.org/10.1002/ 2016JC011698

Inoue R, Suga T, Kouketsu S, Kita T, Hosoda S, Kobayashi T, Sato K, Nakajima H, Kawano T (2016a) Western North Pacific Integrated Physical-Biogeochemical Ocean Observation Experiment (INBOX): Part 1. Specifications and chronology of the S1-INBOX floats. J Mar Res 74 (2): 43-69

JAMSTEC (2009) JAMSTEC OFES (Ocean General Circulation Model for the Earth Simulator) dataset. JAMSTEC. https://doi.org/10.17596/0002029

Johnson GC, McTaggart KE (2010) Equatorial Pacific $13^{\circ} \mathrm{C}$ water eddies in the eastern subtropical South Pacific Ocean. J Phys Oceanogr 40:226-236

Kouketsu S, Yasuda I, Hiroe Y (2007) Three-dimensional structure of frontal waves and associated salinity minimum formation along the Kuroshio Extension. J Phys Oceanogr 37. https://doi.org/10.1175/JPO3026.1

Lee Z, Weidemann A, Kindle J, Arnone R, Carder KL, Davis C (2007) Euphotic zone depth: its derivation and implication to ocean-color remote sensing. J Geophys Res 112:C03009. https://doi.org/10.1029/2006JC003802

Li C, Zhang Z, Zhao W, Tian J (2017) A statistical study on the subthermocline submesoscale eddies in the northwestern Pacific Ocean based on Argo data. J Geophys Res Oceans 122:3586-3598. https://doi.org/10.1002/2016JC012561

Locarnini RA, Mishonov AV, Baranova OK, Boyer TP, Zweng MM, Garcia HE, Reagan JR, Seidov D, Weathers K, Paver CR, Smolyar I (2018) World Ocean Atlas 2018, Volume 1: Temperature, A. Mishonov Technical Ed.; NOAA Atlas NESDIS 81, p 52

Luyten JR, Pedlosky J, Stommel H (1983) The ventilated thermocline. J Phys Oceanogr 13:292-309

Marshall D (1997) Subduction of water masses in an eddying ocean. J Mar Res 55:201-222 
Masumoto $Y$ et al (2004) A fifty-year eddy-resolving simulation of the World Ocean: preliminary outcomes of OFES (OGCM for the Earth Simulator). J Earth Simul 1:35-56

Masuzawa J (1969) Subtropical mode water. Deep Sea Res 16:463-472

Miyake Y, Saruhashi K (1966) On the radio-carbon age of the ocean waters. Pap Met Geophys 17:218-223

Nagano A, Suga T, Kawai Y, Wakita M, Uehara K, Taniguchi K (2016) Ventilation revealed by the observation of dissolved oxygen concentration south of the Kuroshio Extension during 2012-2013. J Oceanogr 72:837-850. https://doi. org/10.1007/s10872-016-0386-9

Nakamura H (1996) A pycnostad on the bottom of the ventilated portion in the central subtropical North Pacific: its distribution and formation. J Oceanogr 52:171-188

Oka E, Toyama K, Suga T (2009) Subduction of North Pacific central mode water associated with subsurface mesoscale eddy. Geophys Research Lett 36: L08607. https://doi.org/10.1029/2009GL037540

Okuda K, Yasuda I, Hiroe Y, Shimizu Y (2001) Structure of subsurface intrusion of the Oyashio water into the Kuroshio Extension and formation process of the North Pacific intermediate water. J Oceanogr 57:121-140

Onogi K et al (2007) The jra-25 reanalysis. J Met Soc Jpn 85:369-432

Oschlies A (2001) Model-derived estimates of new production: newresults point towards lower values. Deep-Sea Res II 48:2173-2197

Pelland NA, Eriksen CC, Lee CM (2013) Subthermocline eddies over the Washington continental slope as observed by Seagliders, 2003-09. J Phys Oceanogr 43(10):2025-2053

Qiu B, Chen S, Klein P, Sasaki H, Sasai Y (2014) Seasonal mesoscale and submesoscale eddy variability along the North Pacific Subtropical Countercurrent. J Phys Oceanogr 44:3079-3098

Ryther JH (1956) Photosynthesis in the ocean as a function of light intensity. Limnol Oceanogr 1(1):61-70. https://doi.org/10.4319/lo.1956.1.1.0061

Sasai Y, Ishida A, Sasaki H, Kawahara S, Uehara H, Yamanaka Y (2006) A global eddy-resolving coupled physical and biological model: physical influences on a marine ecosystem in the North Pacific. Simulation 82:467-474

Sasai Y, Richards K, Ishida A, Sasaki H (2010) Effects of cyclonic mesoscale eddies on the marine ecosystem in the Kuroshio Extension region using an eddyresolving coupled physical-biological model. Ocean Dyn 60:693-704. https:// doi.org/10.1007/s10236-010-0264-8

Sasaki H, Klein P, Qiu B, Sasai Y (2014) Impact of oceanic-scale interactions on the seasonal modulation of ocean dynamics by the atmosphere. Nat Commun 5:5636

Sasaki H, Nonaka M, Masumoto Y, Sasai Y, Uehara H, Sakuma H (2008) An eddyresolving hindcast simulation of the quasiglobal ocean from 1950 to 2003 on the Earth Simulator. In: Hamilton K, Ohfuchi W (eds) High resolution numerical modelling of the atmosphere and ocean, vol chapter 10. Springer, New York, pp 157-185

Spall MA (1995) Frontogenesis, subduction, and cross-front exchange at upper ocean fronts. J Geophys Res 100(C2):2543-2557

Stocker TF (2013) Ch.1. Ocean Circulation and Climate: A 21st Century Perspective. In: Siedler $\mathrm{G}$ et al (eds) International Geophysics, Vol 103. Academic Press, London

Suga T, Aoki Y, Saito H, Hanawa K (2008) Ventilation of the North Pacific subtropical pycnocline and mode water formation. Prog Oceanogr 77:285297. https://doi.org/10.1016/j.pocean.2006.12.005

Suga T, Hanawa K (1995) Interannual variation of North Pacific subtropical mode water in the 137E seciton. J Phys Oceanogr 25:1012-1017

Suga T, Takei Y, Hanawa K (1997) Thermostad distribution in the North Pacific subtropical gyre: the central mode water and the subtropical mode water. J Phys Oceanogr 27:140-152

Sukigara C, Suga T, Saino T, Toyama K, Yanagimoto D, Hanawa K, Shikama N (2011) Biogeochemical evidence of large diapycnal diffusivity associatedwith the subtropical mode water of the North Pacific. J Oceanogr 67:77-85. https://doi.org/10.1007/s10872-011-0008-5

Talley L, Nagata Y, Fujimura M, Kono T, Inagake D, Hirai M, Okuda K (1995) North Pacific intermediate water in the Kuroshio/Oyashio mixed water region. J Phys Oceanogr 25:475-501

Williams RG (2001) Ocean subduction. In: Steele JH, Turekian KK, Thorpe SA (eds) Encyclopedia of ocean sciences. Academic Press, London, pp 1982-1993

Yasuda I, Okuda K, Shimizu Y (1996) Distribution and modification of North Pacific intermediate water in the Kuroshio-Oyashio interfrontal zone. J Phys Oceanogr 26:448-465
Yoshikawa Y, Akitomo K, Awaji T (2001) Formation process of intermediate water in baroclinic current under cooling. J Geophys Res 106(C1):1033-1051

Yoshikawa Y, Lee CM, Thomas LN (2012) The subpolar front of the Japan/East Sea. Part III: competing roles of frontal dynamics and atmospheric forcing in driving ageostrophic vertical circulation and subduction. J Phys Oceanogr 42: 991-1011. https://doi.org/10.1175/JPO-D-11-0154.1

Zhang Z, Li P, Xu L, Li C, Zhao W, Tian J, Qu T (2015) Subthermocline eddies observed by rapid-sampling Argo floats in the subtropical northwestern Pacific Ocean in Spring 2014. Geophys Res Lett 42. https://doi.org/10.1002/ 2015GL064601

Zhu R, Chen Z, Zhang Z, Yang H, Wu L (2020) Subthermocline eddies in the Kuroshio Extension region observed by mooring arrays. J Phys Oceanogr. https://doi.org/10.1175/JPO-D-20-0047.1

Zweng MM, Reagan JR, Seidov D, Boyer TP, Locarnini RA, Garcia HE, Mishonov AV, Baranova OK, Weathers K, Paver CR, Smolyar I (2018) World Ocean Atlas 2018, Volume 2: Salinity, A. Mishonov Technical Ed.; NOAA Atlas NESDIS 82, p 50

\section{Publisher's Note}

Springer Nature remains neutral with regard to jurisdictional claims in published maps and institutional affiliations.

\section{Submit your manuscript to a SpringerOpen ${ }^{\circ}$ journal and benefit from:}

- Convenient online submission

Rigorous peer review

- Open access: articles freely available online

High visibility within the field

- Retaining the copyright to your article

Submit your next manuscript at $>$ springeropen.com 